\title{
Supplemental Columbia River Protection Activities at the Department of Energy Hanford Site: 2008 Technical Review
}

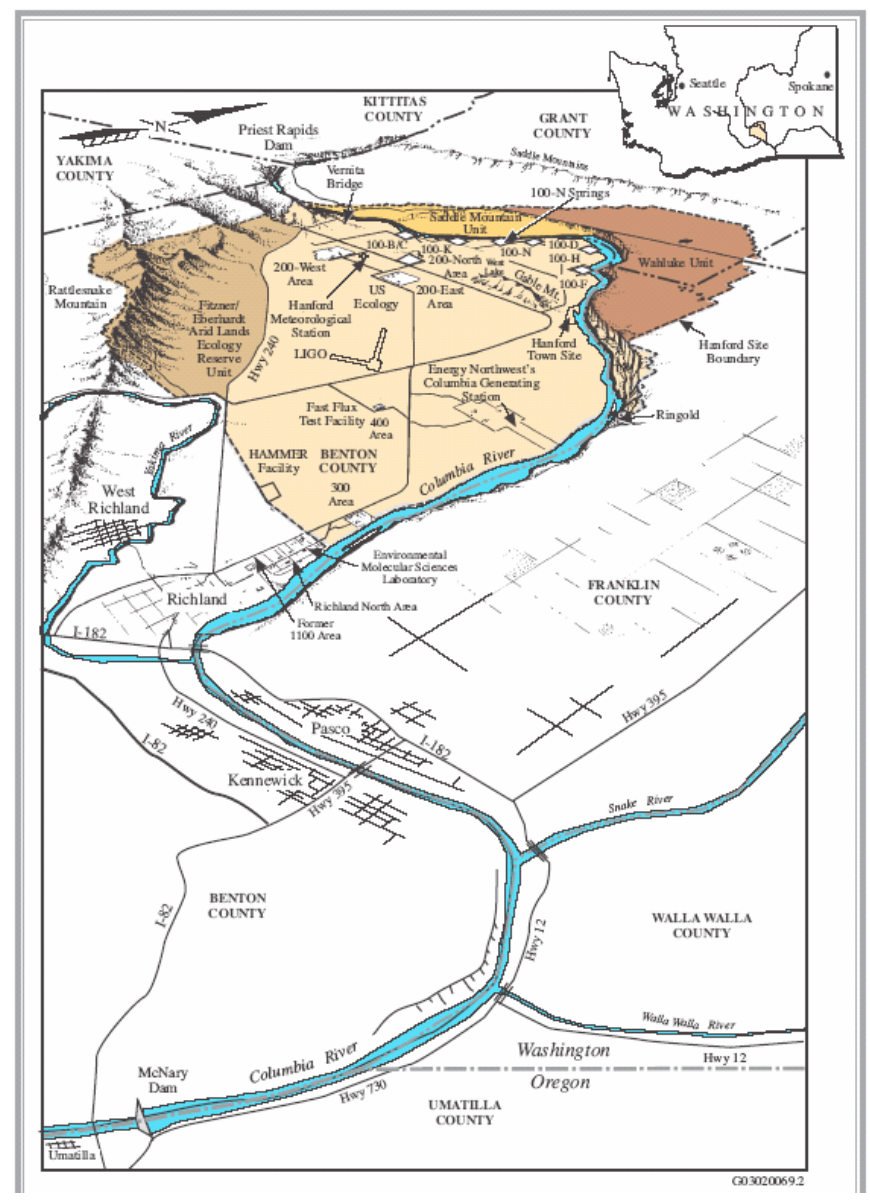

\section{Prepared for}

Department of Energy Office of Groundwater and Soil Clean-up Technology, EM-22 Washington, D.C.

September 2008
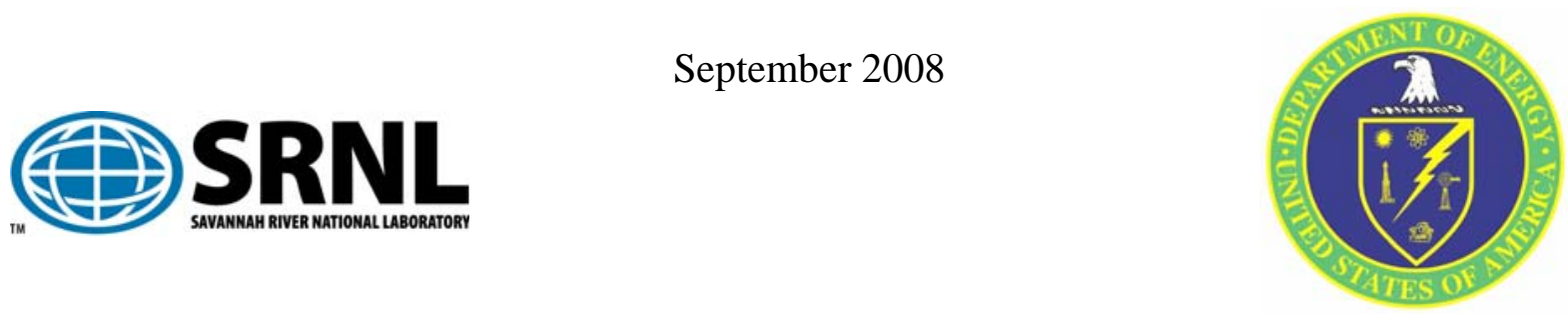

This document was prepared in conjunction with work accomplished under Contract No. DE-AC09-08SR22470 with the U.S. Department of Energy. 


\section{Cover Photo: The Hanford Site and surrounding area (Figure courtesy of the technical personnel at the Hanford Site)}

\section{DISCLAIMER}

This work was prepared under an agreement with and funded by the U.S. Government. While the authors have taken care in the preparation of this report, neither the U. S. Government or its employees, nor any of its contractors, subcontractors or their employees, makes any express or implied: 1 . warranty or assumes any legal liability for the accuracy, completeness, or for the use or results of such use of any information, product, or process disclosed; or 2. representation that such use or results of such use would not infringe privately owned rights; or 3. endorsement or recommendation of any specifically identified commercial product, process, or service. Any views and opinions of authors expressed in this work do not necessarily state or reflect those of the United States Government, or its contractors, or subcontractors.

\section{Printed in the United States of America}

Prepared For U.S. Department of Energy 


\title{
Supplemental Columbia River Protection Activities at the Department of Energy Hanford Site: 2008 Technical Review
}

Authors:

Brian B. Looney ${ }^{1}$, Dawn S. Kaback ${ }^{2}$, Eugene J. LeBoeuf ${ }^{3}$, Joe Rossabi ${ }^{4}$, Karen L. Skubal ${ }^{6}$, David L. Cocke ${ }^{5}$ and Paul C. Deutsch ${ }^{2}$

\author{
Prepared for \\ Blaine Rowley \\ Department of Energy Office of Groundwater and Soil Clean-up \\ Technology, EM-22 \\ Washington, D.C.
}

September 2008

${ }^{1}$ Savannah River National Laboratory, Aiken SC

${ }^{2}$ AMEC Geomatrix, Denver CO and Fresno CA, respectively

${ }^{3}$ Consortium for Risk Evaluation with Stakeholder Participation

(CRESP), Vanderbilt University, Nashville TN

${ }^{4}$ Redox-Tech, Cary NC

${ }^{5}$ Lamar University, Beaumont TX

${ }^{6}$ US DOE EM-22, Washington DC 
SRNL-STI-2008-00424t

Page iv of vi

\{blank page\} 


\section{SUPPLEMENTAL COLUMBIA RIVER PROTECTION ACTIVITIES AT THE DEPARTMENT OF ENERGY HANFORD SITE: 2008 TECHNICAL REVIEW}

\section{Table of Contents}

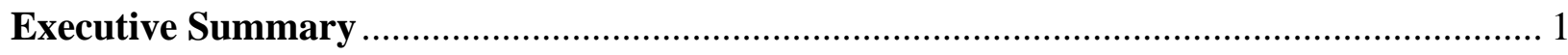

1.0 Introduction and Technical Review Charter ........................................................... 4

2.0 Recommendations for Future Improvements ......................................................... 12

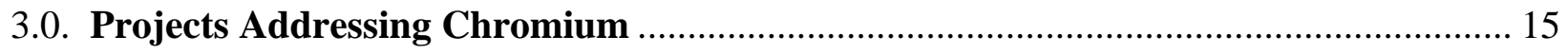

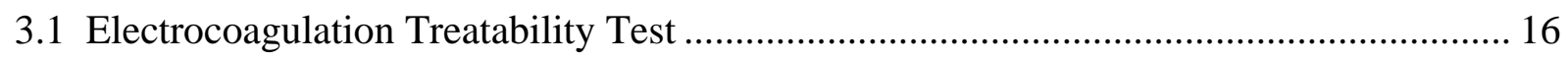

3.2 Geochemical Characterization of Chromium in the Vadose Zone................................... 18

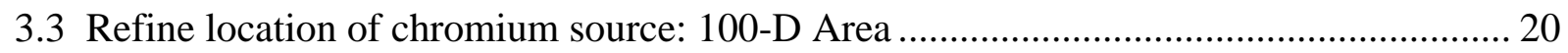

3.4 ISRM Barrier mending with zero valent iron........................................................ 22

3.5 ISRM barrier supplementation with upgradient biostimulation................................... 26

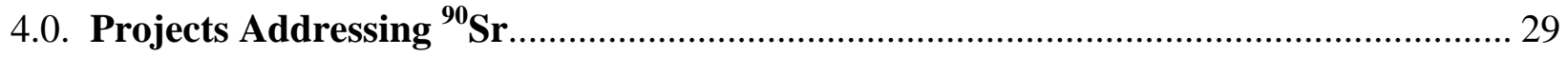

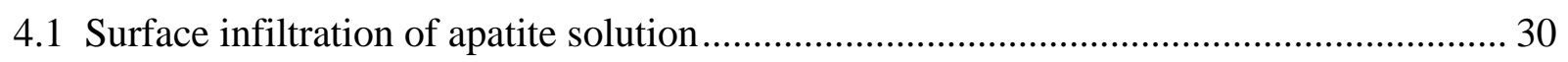

4.2 Phytoextraction (uptake in Coyote Willow) ............................................................. 33

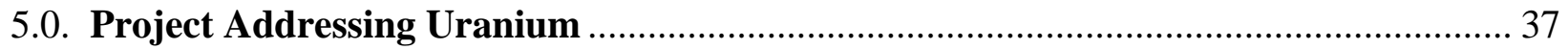

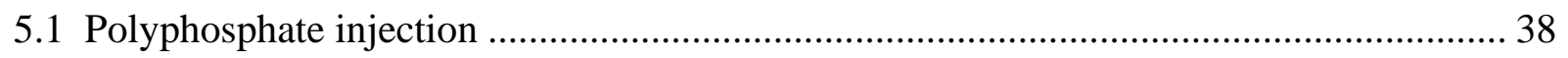

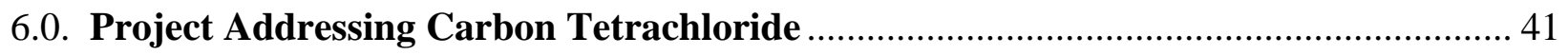

5.1 Measuring hydrolysis/degradation rates................................................................ 42

Appendix A - Short Biographies of the Technical Review Panel Members ....................... 44

Appendix B - Detailed Review of Electrocoagulation ................................................... 49

\section{List of Tables}

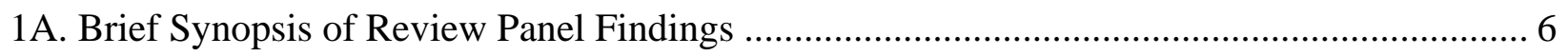

1B. Annotated Synopsis of Review Panel Findings ....................................................... 7-11 
SRNL-STI-2008-00424t

Page vi of vi

\{blank page $\}$ 


\section{Executive Summary}

Beginning in 2006, the US Department of Energy (DOE) supported nine applied research projects to improve the protection of the Columbia River and mitigate the impacts of Hanford Site groundwater. These projects were funded through a supplemental Congressional budget allocation, and are now in various stages of completion in accordance with the research plans. The DOE Office of Environmental Management Groundwater and Soil Cleanup Technologies (EM-22) sponsored a technical peer review meeting for these projects in Richland WA, July 28-31, 2008. The overall objective of the peer review is to provide information to support DOE decisions about the status and potential future application of the various technologies. The charge for the peer review panel was to develop recommendations for each of the nine "technologies." Team members for the July 2008 review were Brian Looney, Gene LeBoeuf, Dawn Kaback, Karen Skubal, Joe Rossabi, Paul Deutsch, and David Cocke. Previous project reviews were held in May 2007 and March-May of 2006. The team used the following four rating categories for projects:

a) Incorporate the technology/strategy in ongoing and future EM activities

b) Finish existing scope of applied research and determine potential for EM activities when research program is finished

c) Discontinue current development activities and do not incorporate technology/strategy into ongoing and future EM activities unless a significant and compelling change in potential viability is documented

d) Supplement original funded work to obtain the data needed to support a DOE decision to incorporate the technology into ongoing and future EM activities

The supplemental funding portfolio included two projects that addressed strontium, five projects that addressed chromium, one project that addressed uranium and one project that addressed carbon tetrachloride. The projects ranged from in situ treatment methods for immobilizing contaminants using chemical-based methods such as phosphate addition, to innovative surface treatment technologies such as electrocoagulation. Total funding for the nine projects was \$9,900,000 in fiscal year (FY) 2006 and \$2,000,000 in FY 2007.

At the Richland meeting, the peer reviewers provided a generally neutral assessment of the projects and overall progress, and a generally positive assessment with regard to the principal investigators meeting their stated research objectives and performing the planned laboratory research and limited field work. Only one project, the Electrocoagulation Treatability Test, received a rating of "discontinue" from the team because the project goals had not been met. Because this particular project has already ended, no action with respect to funding withdrawal is necessary. All other projects were recommended to be finished and/or incorporated into field efforts at Hanford. Specific technical comments and recommendations were provided by the team for each project. 
Importantly, the EM-22 funded scope for all of these projects is nearing completion. Any supplementary funding required to finish or incorporate the various projects may, in some cases, be most appropriately provided through the Hanford operations budget (i.e., “incorporate”) or by the DOE Office of Science (i.e., "supplement” to address basic science issues). The review panel noted that Fluor, the Hanford operations contractor responsible for soil and groundwater cleanup, has been actively engaged in the applied research and has already provided funding to facilitate the final testing and incorporation of several of the technologies. This was commended and the panel encourages continuing such best practices in the future.

"The measure of success is not whether you have a tough problem to deal with, but whether it is the same problem you had last year." John Foster Dulles

This famous quote by a former US Secretary of State provides some context to an overarching technical assessment of the performance for this special portfolio of applied research. According to the enabling language of the House Senate Conference Committee: “... The conferees are concerned about the DOE's efforts to protect contaminants from reaching the Columbia River. Technology used in several remedies is not performing satisfactorily, and there is a lack of new technologies to address contamination issues.” Congress noted that one key problem impeding site closure is poor performance of existing remedies (e.g., pump and treat systems for chromium and uranium, strontium-90 $\left({ }^{90} \mathrm{Sr}\right)$ leaching into the river above guidelines, etc.). The supplemental funding provided an opportunity to address the underperforming technologies in a proactive manner and to increase DOE credibility with regulators, stakeholders, and governments. While the goals of individual projects were often achieved, the reviewers recommend that Hanford and DOE maintain a focus on the broad issue, not "having the same problem you had last year."

Several reviewers noted that a recurring weakness in the effort was a lack of integration and coordination among the various research elements and with the cleanup contractor. Notably, there was a lack of coordination among researchers who were studying similar technologies (e.g., various amendment injection concepts) with overlapping data needs. Long-term success in protecting the Columbia River will require applied research in which every investigator focuses each day on the experiment at hand as well as on the overarching tough problem. Fixing the dysfunctionality of Hanford's environmental activities and encouraging beneficial coordination among the many contributing organizations was a parallel mandate from Congress - of equal importance to the applied technology mandate. In some cases, these projects provided some hopeful signs, such as the partnership and expenditure of support resources by groundwater cleanup contractors such as Fluor Hanford.

More progress is also necessary to assure that projects are managed efficiently and utilize external resources and expertise, as needed. Such expert resources could be used to assist in developing requests for proposals, which include detailed performance metrics, for competitive procurements. Better use of other external resources, such as technical publications and publicly available reports as well as industry-accepted design guides 
would improve the quality of the research and significantly reduce costs - each and every technology does not necessarily need to be revalidated in its entirety and tested in both the lab and the field at Hanford.

This type of applied research requires key uncertainties to be addressed, careful documentation of what is known, and an understanding of how that knowledge can be applied with maximum potential for successful implementation in the field (rather than a focus on research that documents a long list of remaining uncertainties and the need for future research funding). The explicit integration of the supplemental and baseline chromium activities was commended as an early example of this type of progress at Hanford. The review panel recognized that resolving all of the issues associated with protection of the Columbia River based on a two-year portfolio of applied research is unrealistic. Thus, while the panel recommends aspiring to the very high level of performance John Dulles lays out for success - not having the same tough problem as last year - the portfolio of work currently being completed satisfactorily met a reasonable, realistic standard:

“There is no elevator to success. You have to take the stairs.” Anonymous 


\subsection{Introduction and Technical Review Charter}

In November 2005, a conference committee of the US Congress allocated funding to supplement actions to protect the Columbia River from contaminants migrating in the groundwater beneath the DOE Hanford Reservation in Washington State. Toward this end, the US Department of Energy (DOE) Office of Environmental Management (EM) identified and supported nine applied research efforts. The various projects are currently being completed and DOE requested a technical peer review to assist in defining a path forward for the various technologies and strategies. For each technology/strategy, the reviewers provide independent assessment of the progress in meeting applied research goals, as well as a specific path forward statement, or recommendation, related to the need for additional research and the potential for insertion into the EM cleanup program. The path-forward statements are categorized as follows

- Incorporate- The project has yielded significant results and is ready to be implemented in the field or to be incorporated into ongoing site activities. The technology/strategy is promising and addresses an identified need or improves an existing underperforming baseline. This is a "thumbs-up" statement that the applied research was successful and that the technology has a significant potential to improve the Hanford EM baseline. This statement would provide support to DOE to consider the technology and to work with regulators and stakeholders for implementation under the Hanford Site operating baseline. No further EM-22 funding is recommended.

- Finish-The research is generally proceeding as planned and supports the original hypotheses. The principal investigators should complete the project's original scope using the remaining funding. No further EM-22 funding is recommended.

- Discontinue- The project has not been properly managed or has not met its goals and does not warrant continued funding. The current data and documented performance for the technology/strategy are not promising and/or do not substantively address an identified need or improve an existing underperforming baseline technology. The panel recommends that the work should be stopped and should not be further pursued or funded at this time.

- Supplement- The research is promising, but would benefit from additional work to address uncertainties. Additional funding should be sought from Fluor, EM-22 or the DOE Office of Science, as appropriate, so that the project can continue or be extended in scope.

DOE EM, with the assistance of the Legin Group, the Savannah River National Laboratory (SRNL) and the Consortium for Risk Evaluation with Stakeholder Participation (CRESP), identified and assembled a distinguished team of reviewers from industry, universities, and federal laboratories/agencies. The team members were Brian Looney, Gene LeBoeuf, Dawn Kaback, Karen Skubal, Joe Rossabi, Paul Deutsch, and David Cocke. These individuals were selected based on their experience and expertise in the appropriate scientific and engineering disciplines required for the review (see Appendix A); several of the current reviewers participated in previous technical peer review efforts related to the Columbia River research. To support the current peer review 
effort, the team was provided background information including project proposals, progress/final reports and publications. The majority of the team assembled in Richland WA (July 29-30, 2008) for briefings and deliberations with the remaining members participating by teleconference.

The subject technical review covered the following nine research efforts (some of which include more than one funded project):

For hexavalent chromium

Electrocoagulation treatability test

Chromium chemistry - vadose zone

Refine location of chromium source: 100-D Area

ISRM Barrier mending with zero valent iron

ISRM barrier supplementation with upgradient biostimulation

For ${ }^{90} \mathrm{Sr}$

Surface infiltration of apatite solution

Phytoextraction (uptake in Coyote Willow)

\section{For uranium}

Polyphosphate injection

For carbon tetrachloride

Measuring hydrolysis/degradation rates

A brief synopsis and an annotated synopsis of the findings of the review panel are provided in Tables 1A and 1B, respectively. Detailed comments from the various reviewers were collected and composited for each of the nine research efforts; these comments are provided in the sections below in a standardized format. 
Table 1A. Brief Synopsis of Review Panel Findings

\begin{tabular}{|l|c|c|c|}
\cline { 3 - 4 } \multicolumn{1}{l|}{} & Forward Recommendation* & $\begin{array}{c}\text { Meeting Proposed Goals } \\
\text { and Deliverables }\end{array}$ & $\begin{array}{c}\text { Advancing the Protection of } \\
\text { the Columbia River }\end{array}$ \\
\cline { 2 - 4 } Projects Addressing Chromium & & & \\
\hline Electrocoagulation Treatability Test & Discontinue & Poor & Poor \\
\hline Chromium chemistry - vadose zone & Finish & Adequate \\
\hline Refine location of chromium source: 100-D Area & Incorporate & Good & Good \\
\hline ISRM Barrier mending with zero valent iron & Finish & Adequate to Poor & Adequate to Good \\
\hline $\begin{array}{l}\text { ISRM barrier supplementation with upgradient } \\
\text { biostimulation }\end{array}$ & Finish & Good to Adequate \\
\hline Projects Addressing 90Sr & & & Adequate to Poor \\
\hline Surface infiltration of apatite solution & Finish (majority) & Adequate & Adequate \\
\hline Phytoremediation (uptake in Coyote Willow) & Finish & Adequate to Good & Adequate to Good \\
\hline Projects Addressing Uranium & Finish & Adequate & Adequate to Poor \\
\hline Polyphosphate injection & Finish & & \\
\hline Projects Addressing Carbon Tetrachloride & & & \\
\hline Measuring hydrolysis/degradation rates & & & \\
\hline
\end{tabular}

* The recommendations and other assessments represent consensus of the review team unless noted otherwise. 


\begin{tabular}{|c|c|c|c|c|}
\hline & & 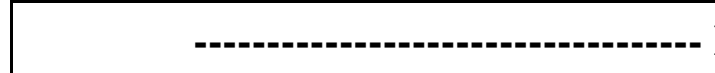 & Review Panel Summary Assessments & 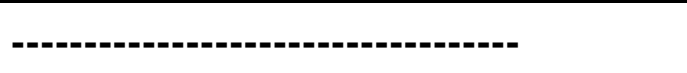 \\
\hline & Forward Recommendation* & $\begin{array}{c}\begin{array}{c}\text { Meeting Proposed Goals and } \\
\text { Deliverables }\end{array} \\
\end{array}$ & $\begin{array}{c}\text { Advancing the Protection of the } \\
\text { Columbia River }\end{array}$ & Overall \\
\hline Projects Addressing Chromium & & & & \\
\hline Electrocoagulation Treatability Test & $\begin{array}{l}\text { Discontinue } \\
\text { Because work on this research project has } \\
\text { already ended, no action to terminate funding } \\
\text { appears necessary. }\end{array}$ & \begin{tabular}{|l|} 
Poor. The project resulted in high costs and \\
poor performance. The system tested \\
appeared to suffer from a lack of \\
understanding or attention to the conceptual \\
design of electrocoagulation. Improved \\
knowledge and training of the field \\
operations staff would have improved the \\
probability of success. The reviewers noted, \\
however that the system had good quality \\
control systems and a professional and \\
polished appearance.
\end{tabular} & $\begin{array}{l}\text { Poor. Minimal contribution to the protection } \\
\text { of the Columbia River because of the poor } \\
\text { performance in meeting goals and } \\
\text { deliverables. Consistent with the earlier } \\
\text { (2006) peer review, the panel recommends } \\
\text { that Hanford continue to evaluate above } \\
\text { ground treatment technologies if needed to } \\
\text { meet the overarching goals for chromium in } \\
\text { the } 100 \text { Areas. Such a forward looking } \\
\text { evaluation could include electrocoagulation } \\
\text { but should have a sharply defined objective to } \\
\text { meet the necessary performance goals and } \\
\text { explicitly include target unit costs less than } \\
\$ 15 \text { per } \mathrm{m}^{3} \text { (i.e., less than approximately } \$ 50 \\
\text { per } 1000 \text { gallons). }\end{array}$ & $\begin{array}{l}\text { Contractor selection process was flawed, } \\
\text { resulting in hiring of an inexperienced } \\
\text { contractor. The tested system was } \\
\text { inadequately conceived and operational } \\
\text { problems resulted in low throughput and poor } \\
\text { quality information. Thus, the panel does not } \\
\text { believe that the resulting data support any } \\
\text { conclusion about the usability of } \\
\text { electrocoagulation. }\end{array}$ \\
\hline Chromium chemistry - vadose zone & $\begin{array}{l}\text { Finish } \\
\text { Additional EM-22 funding is not } \\
\text { recommended. If additional basic science } \\
\text { work assessing microscale chromium } \\
\text { geochemistry is needed, the DOE Office of } \\
\text { Science may be an appropriate source of } \\
\text { funds. }\end{array}$ & $\begin{array}{l}\text { Adequate. The investigators have done a } \\
\text { commendable job in coordinating with other } \\
\text { site contractors but the focus of the work has } \\
\text { been diffuse. These data should be } \\
\text { incorporated into a site conceptual model. } \\
\text { The main finding presented to the team is that } \\
\text { most of the Cr(VI) (circa } 95 \%) \text { is relatively } \\
\text { mobile and leachable. Cr(VI) mobility was } \\
\text { known prior to the funded work -- more focus } \\
\text { on the behaviors of the "other 5\%" is needed } \\
\text { to fully achieve the project goals. These data } \\
\text { should be incorporated into a site conceptual } \\
\text { model }\end{array}$ & $\begin{array}{l}\text { Adequate. The panel believes that the work, } \\
\text { when completed, can contribute to the } \\
\text { protection of the Columbia River. }\end{array}$ & $\begin{array}{l}\text { As the work is completed, the panel } \\
\text { recommends that the investigators structure } \\
\text { their reporting to help interpret current } \\
\text { vadose and groundwater conditions and to } \\
\text { help determine the viability of water flushing } \\
\text { or aqueous reductant application in the } \\
\text { vadose zone or aquifer. Specifically, final } \\
\text { report needs to provide actionable } \\
\text { information to support: a) evaluating both the } \\
\text { positives and negatives of the observed } \\
\text { flushing by aqueous based treatments, b) } \\
\text { identifying/selecting technologies from a } \\
\text { diverse suite of remedial alternatives, and c) } \\
\text { predicting the long term impacts of the } \\
\text { various potential technologies on the tails of } \\
\text { the chromium release and the remediation } \\
\text { timeframe. }\end{array}$ \\
\hline & & & & \\
\hline
\end{tabular}


Table 1B. Annotated Synopsis of Review Panel Findings (continued)

\begin{tabular}{|c|c|c|c|c|}
\hline & \multirow[b]{2}{*}{ Forward Recommendation* } & \multicolumn{3}{|c|}{ 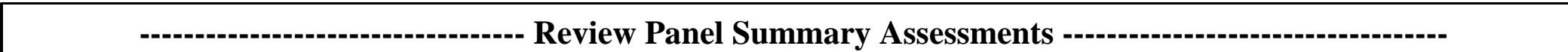 } \\
\hline & & $\begin{array}{c}\text { Meeting Proposed Goals and } \\
\text { Deliverables }\end{array}$ & $\begin{array}{l}\text { Advancing the Protection of the } \\
\text { Columbia River }\end{array}$ & Overall \\
\hline \multicolumn{5}{|l|}{ Projects Addressing Chromium } \\
\hline $\begin{array}{l}\text { Refine location of chromium source: 100-D } \\
\text { Area }\end{array}$ & $\begin{array}{l}\text { Incorporate. } \\
\text { Further refinement of the Cr source in the } \\
100 \mathrm{D} \text { Area (below the current } 100 \mathrm{~m} \times 100 \mathrm{~m} \\
\text { footprint) may be challenging and may not be } \\
\text { cost effective, but the approach used for this } \\
\text { effort should be considered for other areas at } \\
\text { Hanford, for Cr and other contaminants. }\end{array}$ & $\begin{array}{l}\text { Good. The investigators successfully refined } \\
\text { the chromium source location to an area of } \\
\text { approximately } 100 \mathrm{~m} \text { x } 100 \mathrm{~m} \text {. A suite of } \\
\text { relatively standard technologies was used for } \\
\text { the work - importantly previous use of some } \\
\text { of the techniques was limited and the } \\
\text { integrated approach used to synthesize the } \\
\text { information was effective. }\end{array}$ & $\begin{array}{l}\text { Good. This project represents a substantive } \\
\text { advancement in improving protection of the } \\
\text { Columbia River and the effort effectively } \\
\text { implemented the Congressional mandate to } \\
\text { apply alternative technologies toward that } \\
\text { end. The management and implementation of } \\
\text { this project was reasonable. The consensus of } \\
\text { the technical reviewers was positive. }\end{array}$ & $\begin{array}{l}\text { The reviewers commended the project for } \\
\text { collaboration (DOE-operating contractor- } \\
\text { PNNL). }\end{array}$ \\
\hline $\begin{array}{l}\text { ISRM Barrier mending with zero valent } \\
\text { iron }\end{array}$ & $\begin{array}{l}\text { Finish. } \\
\text { Complete field injection as planned and then } \\
\text { have independent panel review results to } \\
\text { support decisions regarding applicability of } \\
\text { the technology at Hanford or elsewhere. No } \\
\text { further EM-22 funding is recommended at } \\
\text { this time. }\end{array}$ & $\begin{array}{l}\text { Adequate to Poor. The original microscale } \\
\text { zero valent iron (ZVI) did not perform as } \\
\text { expected in the bench tests, delaying the } \\
\text { project. The investigators identified a } \\
\text { nanoscale ZVI as a replacement reagent, and } \\
\text { it will be field-tested this year. Several } \\
\text { improvements are needed including: better } \\
\text { communication, improved monitoring for the } \\
\text { field test, more realistic weighting and } \\
\text { assessment criteria, field deployment } \\
\text { experience, improved field test design, etc. }\end{array}$ & $\begin{array}{l}\text { Adequate to Poor. The investigators were } \\
\text { challenged by unforeseen early results and } \\
\text { did a defensible job in modifying their plans } \\
\text { and identifying alternate materials. The } \\
\text { response would have been improved by better } \\
\text { communication and a clearer sensitivity to } \\
\text { cost. The selection of materials for testing } \\
\text { that are } 100 x \text { more expensive than industry } \\
\text { norms and poor field test design may } \\
\text { ultimately make the concept untenable for } \\
\text { full scale application to mend the ISRM } \\
\text { Barrier. }\end{array}$ & $\begin{array}{l}\text { The final report should include defensible } \\
\text { results from the field test including adequate } \\
\text { spatial and temporal monitoring and a } \\
\text { careful, inclusive, and accurate cost } \\
\text { assessment for using the tested/selected } \\
\text { technology. The selected nanoscale iron at } \\
\$ 55 / l b \text { of iron (versus about } \$ 0.55 \text { for a } \\
\text { material that adequately reduced chromium), } \\
\text { may have limited application for this site, for } \\
\text { other DOE sites, or for commercial projects. }\end{array}$ \\
\hline
\end{tabular}




\begin{tabular}{|c|c|c|c|c|}
\hline & & 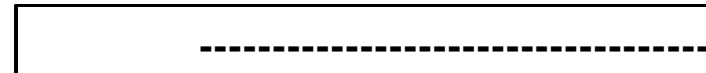 & Review Panel Summary Assessments & s ---------------------------------- \\
\hline & Forward Recommendation* & $\begin{array}{c}\text { Meeting Proposed Goals and } \\
\text { Deliverables }\end{array}$ & \begin{tabular}{|c|} 
Advancing the Protection of the \\
Columbia River
\end{tabular} & Overall \\
\hline Projects Addressing Chromium & & & & \\
\hline $\begin{array}{l}\text { ISRM barrier supplementation with } \\
\text { upgradient biostimulation }\end{array}$ & $\begin{array}{l}\text { Finish } \\
\text { and incorporate into feasibility study and } \\
\text { remedial alternative analysis. Technology } \\
\text { should be considered to support a } \\
\text { comprehensive remediation for Cr(VI) at } 100 \\
\text { D and could be used at other } 100 \text { Area and } \\
\text { Hanford sites. No further EM-22 funding is } \\
\text { recommended at this time. }\end{array}$ & $\begin{array}{l}\text { Good to Adequate. The project has been } \\
\text { performed carefully and on schedule as } \\
\text { described in the funded scope of work. } \\
\text { Progress has been achieved on the goals to } \\
\text { perform laboratory studies and large-scale } \\
\text { field testing to determine the effectiveness of } \\
\text { biostimulation for creating a protective } \\
\text { geochemical zone upgradient of the ISRM } \\
\text { barrier, thereby contributing to a "defense-in- } \\
\text { depth" remediation for the chromium plume } \\
\text { at the 100D Area. Costs could have been } \\
\text { substantially reduced without increasing risk } \\
\text { by making better use of widely available } \\
\text { industry knowledge and available design } \\
\text { guidance. Reviewers expressed concern } \\
\text { about the proposed delivery method and lack } \\
\text { of attention to aquifer heterogeneity. }\end{array}$ & $\begin{array}{l}\text { Adequate. The results can support potential } \\
\text { technology selection and deployment but may } \\
\text { not meet schedule for remedial process } \\
\text { optimization. Better communication and } \\
\text { beneficial use of outside resources would } \\
\text { have accelerated progress to the field test and } \\
\text { provided the potential for a larger test with a } \\
\text { longer and more effective period of } \\
\text { monitoring. The medium-scale laboratory } \\
\text { research was interesting but the results do not } \\
\text { appear to advance knowledge on electron } \\
\text { donor deployment in a significant and } \\
\text { actionable manner. The slowed the project } \\
\text { schedule may not meet contractor schedule } \\
\text { requirements. }\end{array}$ & $\begin{array}{l}\text { The reviewers commended the researchers on } \\
\text { both work quality and work control. Future } \\
\text { studies of this type should be designed to } \\
\text { better incorporate and utilize available offsite } \\
\text { data and resources. }\end{array}$ \\
\hline Projects Addressing 90Sr & & & & \\
\hline Surface infiltration of apatite solution & $\begin{array}{l}\text { The majority favored Finish with a minority } \\
\text { of the panel advocating Discontinue. (split } \\
\text { finding) Supplemental EM-22 funding is not } \\
\text { recommended at this time. Interesting basic } \\
\text { science issues identified in the research } \\
\text { should be funded by the Office of Science as } \\
\text { necessary. }\end{array}$ & $\begin{array}{l}\text { Adequate. This project produced several good } \\
\text { quality experiments that have provided } \\
\text { important information including measured } \\
\text { rates of } 90 \text { Sr incorporation into apatite and } \\
\text { required apatite mass loading to sequester } \\
\text { 90 } 9 \text { Sr. Unfortunately, microcosm and small } \\
\text { sandbox experiments are of limited use in } \\
\text { developing full scale field application } \\
\text { parameters. The project has spent resources } \\
\text { examining various tangents and basic issues } \\
\text { that are not closely linked to the overarching } \\
\text { applied science objectives. Better } \\
\text { communication and coordination with the } \\
\text { polyphosphate researchers would have been } \\
\text { beneficial. }\end{array}$ & $\begin{array}{l}\text { Adequate to Poor. The focus was almost } \\
\text { entirely on lab tests. A field research } \\
\text { component, or a clear path toward moving } \\
\text { the concept to the field, is needed to make } \\
\text { this work relevant to potential use. Lack of a } \\
\text { field component was troublesome to the } \\
\text { reviewers because this vadose targeted } \\
\text { research was positioned as an extension of } \\
\text { ongoing full-scale deployment of apatite } \\
\text { forming solution below the water table - } \\
\text { much of the previous lab research should } \\
\text { support this variant. Performance metrics } \\
\text { and a strategy related to how the information } \\
\text { generated in this research would improve } \\
\text { protection of the Columbia River were weak. }\end{array}$ & $\begin{array}{l}\text { If DOE moves forward to complete this effort } \\
\text { with the in-place EM-22 funding, the } \\
\text { researchers should consider the peer review } \\
\text { comments to the extent practicable. At a } \\
\text { minimum, the researchers should produce an } \\
\text { applied science product that identifies the } \\
\text { state of knowledge ("what is known") and } \\
\text { how that knowledge supports actions to } \\
\text { protect the Columbia River. This was a proof } \\
\text { of-principle project that did not work very } \\
\text { well; thus raising concerns about the entire } \\
\text { project being successfully deployed. }\end{array}$ \\
\hline
\end{tabular}


Table 1B. Annotated Synopsis of Review Panel Findings (continued)

\begin{tabular}{|c|c|c|c|c|}
\hline & & 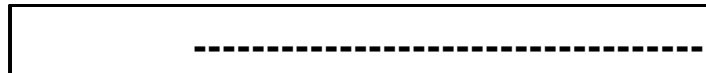 & Review Panel Summary Assessments & S ------------------------------------ \\
\hline & Forward Recommendation* & $\begin{array}{c}\text { Meeting Proposed Goals and } \\
\text { Deliverables }\end{array}$ & \begin{tabular}{|c|}
$\begin{array}{c}\text { Advancing the Protection of the } \\
\text { Columbia River }\end{array}$ \\
\end{tabular} & Overall \\
\hline Projects Addressing 90Sr & & & & \\
\hline $\begin{array}{l}\text { Phytoremediation (uptake in Coyote } \\
\text { Willow) }\end{array}$ & $\begin{array}{l}\text { Finish } \\
\text { both subparts of this project and evaluate data } \\
\text { to determine viability and acceptability for } \\
\text { application. The review panel identified } \\
\text { (below) several suggested activities to } \\
\text { improve the potential applicability and } \\
\text { viability of phytoextraction, but the panel } \\
\text { does not necessarily recommend additional } \\
\text { EM-22 funding at this time unless a clear } \\
\text { signal can be obtained from regulators and } \\
\text { stakeholders that they are likely to permit the } \\
\text { concept based on the already funded } \\
\text { activities. }\end{array}$ & $\begin{array}{l}\text { Adequate to Good. This effort comprises two } \\
\text { separately funded projects: a) a field study to } \\
\text { address questions related to optimal } \\
\text { management of Coyote willow to support } \\
\text { deployment for phytoextraction of 90Sr, and } \\
\text { b) a food chain uptake and transfer study. } \\
\text { Both projects are addressed together in this } \\
\text { section. The reviewers note that reasonable } \\
\text { progress has been made on this research } \\
\text { despite flooding. }\end{array}$ & $\begin{array}{l}\text { Adequate. Depth profiles of }{ }^{90} \text { Sr have been } \\
\text { underutilized in this effort. Similarly, the } \\
\text { distribution of willow root biomass for trees } \\
\text { grown in the } 100 \mathrm{~K} \text { Area riparian test plot } \\
\text { were not determined. Some of the biomass } \\
\text { uptake studies are not complete and public } \\
\text { acceptance remains uncertain. }\end{array}$ & $\begin{array}{l}\text { The project has highlighted the difficulty of } \\
\text { working in a dynamic and variable } \\
\text { environment. These data suggest that native } \\
\text { plants, such as Coyote willow, have the } \\
\text { potential to perform well and to provide some } \\
\text { robustness if incorporated into a } \\
\text { comprehensive remediation strategy. A } \\
\text { lifecycle conceptual approach, supported by } \\
\text { clear, concise and compelling information, a } \\
\text { monitoring plan, and contingencies are } \\
\text { crucial to such acceptance. Even if the } \\
\text { research documents technical feasibility, } \\
\text { stakeholders are likely to express significant } \\
\text { discomfort extracting a contaminant } \\
\text { radionuclide into a surface ecosystem on the } \\
\text { shoreline of the Columbia River. }\end{array}$ \\
\hline Project Addressing Uranium & & & & \\
\hline Polyphosphate injection & $\begin{array}{l}\text { Finish. } \\
\text { Any future work deemed necessary by DOE } \\
\text { (e.g., to verify the long-term stability of } \\
\text { uranium-bearing minerals produced by } \\
\text { polyphosphate amendments in the vadose } \\
\text { zone) would be appropriate for funding } \\
\text { through the Office of Science, possibly as } \\
\text { part of the activities at field research site in } \\
\text { the } 300 \text { Area of Hanford. }\end{array}$ & $\begin{array}{l}\text { Adequate. High quality lab studies were } \\
\text { completed. The polyphosphate amendment, } \\
\text { as applied in the field, did not form sufficient } \\
\text { mineral precipitates for saturated zone } \\
\text { treatment in the } 300 \text { Area. There were a } \\
\text { variety of reasonable and plausible } \\
\text { hypotheses about the underperformance. In } \\
\text { general, however, the dominant factor } \\
\text { controlling underperformance was the } \\
\text { hydrogeologic and geochemical heterogeneity } \\
\text { found at the field scale. }\end{array}$ & $\begin{array}{l}\text { Adequate to Poor. The underperformance in a } \\
\text { real-world setting highlights the limitation of } \\
\text { attempting to resolve all technical } \\
\text { uncertainties through lab and column testing. } \\
\text { The review panel emphasized the need for } \\
\text { well conceived performance metrics, and a } \\
\text { focused plan that moves steadily through lab } \\
\text { and column studies toward well designed and } \\
\text { controlled field pilot tests. Techniques such } \\
\text { as push pull testing and other relatively low } \\
\text { cost field tests could eliminate a portion of } \\
\text { the lab work and improve the potential for } \\
\text { success and implementation. }\end{array}$ & $\begin{array}{l}\text { Based on the data, the panel concluded that } \\
\text { the technology, as originally scoped for } \\
\text { groundwater treatment, does not currently } \\
\text { have sufficient information to justify } \\
\text { deployment. Further, the underperformance } \\
\text { highlights the general need for Hanford and } \\
\text { PNNL to develop an approach for applied } \\
\text { research that emphasized moving out of the } \\
\text { laboratory and into the field in an efficient } \\
\text { and effective manner. }\end{array}$ \\
\hline
\end{tabular}


Table 1B. Annotated Synopsis of Review Panel Findings (continued)

\begin{tabular}{|c|c|c|c|c|}
\hline & & -----------------------------------.' & - Review Panel Summary Assessments & 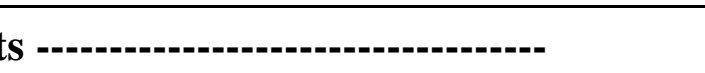 \\
\hline & Forward Recommendation* & $\begin{array}{c}\text { Meeting Proposed Goals and } \\
\text { Deliverables }\end{array}$ & $\begin{array}{c}\text { Advancing the Protection of the } \\
\text { Columbia River }\end{array}$ & Overall \\
\hline $\begin{array}{l}\text { Project Addressing Carbon } \\
\text { Tetrachloride }\end{array}$ & & & & \\
\hline Measuring hydrolysis/degradation rates & $\begin{array}{l}\text { Finish. } \\
\text { As originally scheduled, this work plan } \\
\text { spanned } 4 \text { to } 6 \text { years, with EM-22 Columbia } \\
\text { River supplemental funding for } 2 \text { years and } \\
\text { an alternate source of funding in the out years } \\
\text { if "tangible progress is demonstrated." The } \\
\text { project has performed well and the review } \\
\text { panel supports completing this effort. }\end{array}$ & $\begin{array}{l}\text { Good. The investigators have done a } \\
\text { commendable job in the organizing and } \\
\text { carrying out the work. The PNNL } \\
\text { collaboration with academia was a notable } \\
\text { positive feature of this project, although it } \\
\text { was not clear why so much of the work was } \\
\text { duplicated in its entirety at both institutions. } \\
\text { Some reviewers expressed concern over } \\
\text { specific details of the project, but the general } \\
\text { consensus was positive. }\end{array}$ & $\begin{array}{l}\text { Adequate to Good. In this case, physical } \\
\text { chemistry research on hydrolysis rates may be } \\
\text { the key to a rational sitewide strategy for the } \\
\text { organic solvent plume in the groundwater at } \\
\text { Hanford. To assure that maximum benefit is } \\
\text { realized from the funding the review panel } \\
\text { recommended that the researchers focus } \\
\text { additional effort on how the small scale tests } \\
\text { can be applied to a groundwater plume with a } \\
\text { footprint of several square kilometers. }\end{array}$ & $\begin{array}{l}\text { This study addresses one of the largest and } \\
\text { most challenging plumes at Hanford and the } \\
\text { data may be critical in resolving cleanup } \\
\text { strategy at the Hanford site. The hydrolysis } \\
\text { rate for carbon tetrachloride and chloroform } \\
\text { in the aquifer system will determine if the } \\
\text { solvent plumes in the groundwater will } \\
\text { stabilize (and then shrink over time) prior to } \\
\text { impacting the Columbia River. That } \\
\text { determination, in turn, will help determine if } \\
\text { a complex-expensive groundwater treatment } \\
\text { strategy for organic solvents is required, or if } \\
\text { a strategy that relies on natural attenuation } \\
\text { including hydrolysis to protect the Columbia } \\
\text { River is viable. }\end{array}$ \\
\hline
\end{tabular}

* The recommendations and other assessments represent consensus of the review team unless noted otherwise. 


\subsection{Recommendations for Future Improvements}

While the Columbia River Projects have resulted in significant advances in understanding related to characterization and remediation of groundwater near the Columbia River, there are several general recommendations related to improvements that could be implemented for future EM-22 programs and projects. These recommendations can be categorized into improvements related to 1) project relevance, 2) project management, and 3) project scope.

\section{Project Relevance}

When DOE EM's science and technology organization was first formed in 1989, much of the focus of the program was on development of new in situ technologies in a market where in situ approaches were only in their infancy. There was little emphasis at that time as to integration with DOE site cleanup projects and schedules, as there was ample time for that in the future. As the DOE sites worked to fully characterize their groundwater and soil problems, new technologies were demonstrated as proof of principle tests. As the DOE cleanup managers implemented technologies to meet more pressing schedules in the late 1990s and early 2000s, the need for better integration of technology development into the cleanup program became evident. By 2008, this is a critical issue, as in many cases typical 2-4 year technology development projects do not fit into the existing site cleanup schedule. As such, the DOE EM-22 Program needs to evolve to meet pressing needs in a time sensitive schedule.

This doesn't negate the need for further technology development conducted within the Office of Science to consider scientific issues related to soil and groundwater remediation or within the EM-22 Program to facilitate innovative designs and uses of existing and emerging technologies to meet site specific needs within an expedited schedule. The review panel has recognized that some of the projects funded under the Columbia River Program are not going to provide technology solutions that meet current schedule requirements, although they may provide information for future changes to the remedial systems.

As such the review panel recommends a stronger focus on technology insertion into the cleanup program for future EM-22 projects. As an example, in the late 1990's the precursor to EM-20 sponsored a program called the Accelerated Site Technology Deployment Program (ASTD), which required proposals to be submitted by site cleanup managers with a commitment to provide leveraged funds to conduct a project that could be completed within the required schedule. The review panel recommends that DOE consider reinstituting such a program or implementing a similar-alternative type of programmatic activity to ensure cleanup success.

\section{Project Management}

While DOE established a credible process, which included independent review of the proposals, to select projects to address Congressional concerns about improving groundwater quality prior to its entry into the Columbia River, the review panel provides the following recommendations related to project management. 
- The request for proposal process should identify and describe performance goals, specific objectives, and detailed metrics by which to measure progress towards meeting the objectives in the proposals submitted for consideration. In addition, an option for a "go/no go" point during project implementation should be considered as a management tool. Incorporation of this concept may require revision of the approach to administering the budget for these types of projects.

- DOE should establish a robust review process during project implementation that includes 1) principal investigator response to specific recommendations made by the review panel during the proposal review process to ensure project scopes of work have incorporated appropriate recommendations or if not, why not, 2) ongoing review by the peer review panel, via teleconference, during project implementation, and 3) a complete final review of the projects by the independent peer review panel to include review of the final reports prepared by the principal investigators.

\section{Project Scope}

As we reviewed each of the projects during the peer review workshop, a number of common themes were identified. Thus, the following provides recommendations for improvements that address these common themes.

- Each project should have performance goals, specific objectives, as well as detailed metrics that can be used to measure progress towards meeting the objectives. In many of the projects reviewed, detailed metrics were not fully developed and/or reported to the review panel. Close coordination and integration with site cleanup project schedules should be included in the objectives and metrics for each of the projects.

- Delivery of amendments to the subsurface is a significant issue in all of the in situ remediation projects. This delivery issue relates to the scale up from laboratory to field scale and was identified in a number of the projects. When conducting laboratory column studies, much is learned about the chemical or biological reactions taking places within a small volume, but as these tests are scaled up to field scale, taking into account much more heterogeneous conditions, the delivery of amendments is no longer optimized. Prior review panel recommendations were not explicitly addressed in a number of cases; for example, 1) simple injection was performed rather than considering alternatives such as push-pull delivery (polyphosphate), 2) simple injection was used rather than the recommended infiltration from the shallow subsurface (biostimulation), 3) injection was performed throughout the aquifer thickness rather than in targeted high-flow zones, as suggested (ZVI mending).

- A more robust performance monitoring effort should be included for in situ projects. Examples of monitoring concerns not addressed in the existing projects include 1) insufficient down-gradient monitoring, 2) lack of post-treatment sampling, and 3) lack of sampling of key constituents other than the contaminants of concern.

- The review panel is concerned about transition from laboratory to the field. Have the laboratory tests been designed robustly enough to support the transition or is there a need to involve scientists and engineers who have significant field 
experience, e.g., industry consultants, to assist with field design? This was noted for a number of in situ projects, in which amendments need to be effectively delivered to heterogeneous media at the Hanford Site.

- When projects require preparation of an RFP for outside contracts in a highly specialized field, such as electrocoagulation or zero-valent iron injection, it is highly recommended that the DOE prime contractor utilize the services of an expert in the field to assist with preparation of the RFP, review of proposals, and review of the project. 


\subsection{Projects Addressing Chromium}

Five applied research projects were performed to address chromium in the groundwater in the Hanford 100 Areas adjacent to the Columbia River. These projects were selected to integrate with an overall chromium strategy at Hanford that applies multiple technologies in a coordinated and synergistic manner. The technical review panel commends this type of integrations. The five chromium projects were:

o Electrocoagulation treatability test (3.1)

o Chromium chemistry - vadose zone (3.2)

o Refine location of chromium source: 100-D Area (3.3)

o ISRM Barrier mending with zero valent iron (3.4)

o ISRM barrier supplementation with upgradient biostimulation (3.5) 


\subsection{Electrocoagulation Treatability Test}

Consensus Recommendation - Discontinue. Because this research project has already ended, no action to terminate funding is necessary.

Summary of Review: The technical reviewers determined that this project did not meet its objectives and that, for a variety of reasons, the effort did not provide useful information about the performance of electrocoagulation (EC). The tested system was inadequately conceived and operational problems resulted in low throughput and poor quality information. Thus, the panel does not believe that the data support any conclusion about the usability of EC. Many of the challenges and issues encountered by the project were highlighted as areas of concern in an initial technical peer review in 2006 - this early review could have been used beneficially by the project team to minimize the problems encountered. The overall cost of this one project was over $15 \%$ of the supplemental Congressional allocation so the underperformance of this effort is significant. Importantly, the unit costs for this technology, as applied at Hanford, were several orders of magnitude above industry norms. Consistent with the 2006 peer review, the panel recommends that Hanford continue to evaluate above ground treatment technologies if needed to meet the overarching goals for chromium in the 100 Areas. Such a forward looking evaluation should have a sharply defined objective to meet the necessary performance goals and explicitly including target total treatment costs less than $\$ 15$ per $\mathrm{m}^{3}$ (i.e., less than approximately $\$ 50$ per 1000 gallons). Note that a detailed evaluation of the EC project is provided in Appendix B.

Objectives: The primary objective of the research was to determine whether EC is a viable method for treating the 100D Area chromium plume. This technology has been proven for treating water and has been used to remove a variety of suspended solids and dissolved pollutants from municipal and industrial water systems. Performance goals for the research included attaining chromium levels of less than $20 \mu \mathrm{g} / \mathrm{L}$ in treated groundwater; determining system waste disposal requirements; determining $\operatorname{Cr}(\mathrm{VI})$ removal efficiency; demonstrating safe and reliable system operation; acquiring operational data to support future system scale-up; and estimating total treatment costs on a volumetric and contaminant removal basis. EC was intended to accelerate site cleanup by treating greater volumes and higher concentrations of chromium-contaminated groundwater than the existing system, based upon ion exchange, can process. The EM funded project cost was $\$ 2,200 \mathrm{~K}$ and this was supplemented by Hanford operations funds as needed to coordinate safety and field implementation. The project has been completed.

Project Performance: During field testing, the technology (EC) was able to reduce $\mathrm{Cr}(\mathrm{VI})$ below acceptable levels $(<20 \mu \mathrm{g} / \mathrm{l})$ in both groundwater (starting concentrations approximately $200 \mu \mathrm{g} / \mathrm{l}$ ) and spiked groundwater (concentrations exceeding $2000 \mu \mathrm{g} / \mathrm{l} \mathrm{l}$ ). Although EC was able to satisfactorily reduce $\operatorname{Cr}(\mathrm{VI})$ concentrations in the site groundwater, a large proportion of the project was spent on optimizing standard water and waste water treatment unit operations (e.g., filters, aerators, etc.) to enable the tested technology (EC) to function. Difficulties in obtaining and maintaining performance of the 
secondary, supporting processes precluded an adequate assessment of the performance and optimization of EC, the principal technology. The field study did not provide adequate data to determine whether electrocoagulation is a viable technology. Improper sample characterization (e.g., a lack of duplicate field samples, improper reagents and procedures for ferrous iron analysis), improper system operation (e.g., discontinuation of air sparging and the addition of excess polymer into the EC treatment train), insufficient vendor experience/support, and a general lack of project oversight led to inadequate final water quality and injection well fouling. Because of poor project practices, some of the results of this study (for example, the treatment cost estimates and the system's inconsistency in attaining effluent requirements in a single pass) do not represent endpoints that could have been achieved by a properly-operated system. Thus, the question of whether EC is feasible for 100D Area groundwater treatment was never answered.

Lessons Learned: The contractor selected was not expert in the field and therefore was unable to answer some critical technology questions with the available time and budget. The critical questions that were not effectively answered include:

1. Is the technology more cost effective than the currently implemented technology (ion exchange).

2. Is the technology more cost effective than alternative technologies. Available resources, such as independent EC experts, were not beneficially used during this project. More focus on general industry norms (e.g., standard unit costs), improved oversight, and more detailed up front contingency planning could have improved performance. An appropriately crafted request for proposal could have precluded selection of an inexperienced subcontractor.

In addition, the previous review panel recommended an alternatives analysis be conducted prior to selection of EC for the demonstration. This technical evaluation could have improved the likelihood for successful implementation at Hanford by helping to focus performance metrics.

Path Forward: Although it was determined that EC can adequately reduce $\mathrm{Cr}(\mathrm{VI})$ concentrations, necessary information on performance in this application was not obtained within the allocated and adequate budget. It is not clear that the contractor selected for this work would be able to obtain this information without an additional large amount of funding. If an alternative expert contractor were selected at this point to correctly complete the test objectives, they would necessarily incur duplicative project startup costs with no clear promise of a significant advantage of EC in comparison with the baseline technology or alternative technologies. Additional assessments of the use of EC for chromium treatment at Hanford are not warranted at this time unless a compelling evaluation documents a significant advantage over alternative methods. 


\subsection{Geochemical Characterization of Chromium in the Vadose Zone}

Consensus Recommendation - Finish; additional EM-22 funding is not recommended. If additional basic science work assessing microscale chromium geochemistry is needed, the DOE Office of Science may be an appropriate source of funds.

Summary of Review The researchers did a good job in coordinating their applied research tasks with related site field activities and were able to obtain actual site sediment packed in columns for leaching tests. They also successfully employed a suite of microscopy and spectroscopy tools to determine the characteristics and forms of chromium in contaminated soils. To date, the research focus has been somewhat diffuse, however, limiting the utility of the information. Importantly, one of the primary findings - that most of the $\mathrm{Cr}(\mathrm{VI})$ will leach when flushed with aqueous solutions, such as calcium polysulfide - was the conceptual model of expected behavior prior to this research. In earlier peer reviews, a clear and organized focus on long-term leaching, the tails of the chromium flushing, was encouraged. The state-of-the-art geochemical studies and the various leaching tests with reductant solutions have only modestly advanced the understanding of the long-term potential for chromium release. As this work is completed, we recommend that the results be put in context using simple scoping models and realistic field parameters. Further, we recommend that the results be structured to help understand current vadose and groundwater conditions and to support future vadose treatment decisions. When completed, the effort needs to provide unbiased and actionable information to: a) evaluate both the positives and negatives of the observed flushing by aqueous based treatments, b) support technology identification/selection from a diverse suite of remedial alternatives, and c) emphasize the long term impacts of the various potential technologies on the tails of the release and the remediation timeframe for the underlying groundwater.

Objectives: The primary objectives of this study were to determine the leaching characteristics of hexavalent chromium in contaminated sediments collected from 100 Area spill sites; to use leaching studies and microscale characterization to assess geochemical associations contributing to $\mathrm{Cr}(\mathrm{VI})$ retention in 100 Area soil; and to contribute to a conceptual model of hexavalent chromium geochemistry at the site. The EM funded project cost was $\$ 500 \mathrm{~K}$.

Project Performance: The project successfully measured the leaching behavior of chromium from 100 Area soil samples. Perhaps the clearest finding of the research was that most of the $\mathrm{Cr}(\mathrm{VI})$ is mobilized during the first wash or exposure to advective aqueous flows. There was an emphasis in the reporting that polysulfide solution (a commonly used reducing agent) flushing was characteristically responsible for a significant amount of $\mathrm{Cr}$ transport ahead of the reducing reaction. The reviewers noted that the results appear to indicate that any aqueous fluid would behave similarly and move a significant fraction (e.g. 95\%) of the $\mathrm{Cr}(\mathrm{VI})$ during first flush. Notably, the mobility and flushability of $\mathrm{Cr}(\mathrm{VI})$ were well known at the beginning of this research and would factor into any remediation design. Focusing the principal reported findings of supplemental research $(\$ 500,000)$ on processes that are well known and documented in 
the literature does not provide the best applied science value. The more interesting information from the tailing of the leaching experiments has not been sufficiently emphasized. These data are important for determining whether aqueous phase reductant application is appropriate for treating the $\mathrm{Cr}$ in the long-term. As suggested by $\mathrm{Dr}$. Kaback during the review, a recirculating soil flushing system (with capture and surface treatment) may be appropriate for bulk removal of chromium from the vadose zone, given the metal's demonstrated leachability. Further, it would have been beneficial for the researchers to examine more thoroughly the post-flush leachability and the geochemistry of chromium following the application of pure water and select aqueous treatment reagents such as polysulfide. One of the findings presented by the investigators, suggesting that gas phase reduction would be a more promising remedial technology, is not supported by data collected in this program and is speculative.

Basic science studies and microscale characterization of chromium-contaminated sediments were performed using X-ray microprobe (XMP), X-ray absorption near edge structure (XANES), scanning electron microscopy (SEM) and X-ray photoelectron spectroscopy (XPS) and similar techniques. Although it is potentially useful to understand how hexavalent chromium is retained in vadose sediments, the investigators have not yet demonstrated that their work advances a more realistic and useful conceptual model for chromium geochemistry in the 100 Area vadose zone. The XMP method, for example, examined a $300 \mu \mathrm{m} \times 300 \mu \mathrm{m}$ area of soil sample, far too small an area of interrogation for meaningful extrapolation to macroscopic behavior. No attempt was made to justify the "representativeness" or field relevance of grain-scale samples.

Lessons Learned: It is beneficial to clearly define the focus and goals of this type of applied research and how they address the target problem. This project was initially developed with a broad and relatively general focus - to find out about the chromium controlling geochemistry in 100 Area vadose sediments. Specific hypotheses and how the proposed measurements would provide actionable changes to the status quo were not articulated up front. As a result, the project has generated a large amount of state of the art data but the clear linkage to improving the protection of the Columbia River has not been made.

Path Forward: Finish the report. Include a discussion of the implications for remediation strategies that might use subsurface injections in the vadose zone. If there is evidence that strong reducing agents are characteristically responsible for mobilizing $\mathrm{Cr}$, it needs to be shown and explained. Also include a more complete analysis of the tail of the leaching experiments. The information should be structured to help interpret current vadose and groundwater conditions and to help determine the viability of water flushing or aqueous reductant application in the vadose zone. Specifically, final report needs to provide actionable information to support: a) evaluating both the positives and negatives of the observed flushing by aqueous based treatments, b) technology identification/selection from a diverse suite of remedial alternatives, and c) predicting the long term impacts of the various potential technologies on the tails of the chromium release and the remediation timeframe. 


\subsection{Refine location of chromium source: 100-D Area}

Consensus Recommendation - Incorporate - for other areas at Hanford, for chromium and other contaminants.

Summary of Review: The investigators successfully refined the chromium source location to an area of approximately $100 \mathrm{~m} \times 100 \mathrm{~m}$. A suite of relatively standard technologies was used for the work - importantly some of the techniques had had limited application in the prior baseline activities and the integrated approach used to synthesize the information was effective. Thus, this project represents a substantive advancement in improving protection of the Columbia River and the effort effectively implemented the Congressional mandate to apply alternative technologies toward that end. The management and implementation of this project was reasonable and the consensus of the technical reviewers was positive. The technical review panel encourages incorporating the source location information into Hanford decisionmaking on potential remedies for chromium. Notably, the technical review panel cautions that refining the source to a relatively small footprint does not automatically imply that physical removal (excavation) is appropriate or preferred - such excavation, even if carefully implemented would likely result in adverse collateral damage to the environment particularly when performed adjacent to the Columbia River. The panel recommends a scientific, technically-based examination of alternative technologies to address the refined source area. This examination should include diverse approaches including: physical and chemical processes that stabilize and detoxify chromium, physical and chemical processes that reduce chromium flux, and/or physical and chemical processes that remove chromium. Based on the data, the panel indicated that continuing a formal drilling, sampling, and data analysis program in the 100-D Area may not be cost effective and may not substantially further refine the source area. For 100-D Area, the panel encouraged use of opportunistic data (e.g., observations during pipeline and facility decommissioning) in the future as a promising approach to reduce the footprint below $100 \mathrm{~m} \times 100 \mathrm{~m}$. Nonetheless, the reviewers strongly encourage incorporating the drilling, sampling, and data analysis strategy developed in this supplemental activity to help address other areas and target contaminants at Hanford.

Objectives: The main project goal was to locate the chromium source of the southwestern plume in the 100-D Area by using drilling and trenching methods, excavation of surface zones, and groundwater monitoring. Cost-effective standard drilling and sampling technologies were to be used for sample acquisition. Soils collected during this activity were to be provided to researchers to support parallel efforts to characterize chromium geochemistry and behavior in the vadose zone. The EM funded project cost was $\$ 1,250 \mathrm{~K}$. The project has been completed.

Project Performance: The December 2006 peer review of the original vadose source delineation proposal recommended dramatically revising the proposal. Rather than surface geophysics or other speculative methods, recommendations were made to begin investigations close to known source areas and install additional boreholes based on an 
understanding of $\mathrm{Cr}$ transport, fate, and form in the vadose zone. The proposal was revised consistent with those recommendations.

During the project, historical geochemical and hydrogeologic data were analyzed to backtrack to the likely $\mathrm{Cr}$ source in $100 \mathrm{D}$ Area. Seven boreholes were then drilled near the likely source. Samples collected from these boreholes had significantly higher concentrations than previous samples indicating proximity to the source. After 6 months of monitoring 7 new wells, an additional 4 boreholes were drilled using a similar strategy. These additional boreholes further narrowed the source location and potential treatment area to less than 1 hectare. This method was more definitive and therefore more useful than methods with higher uncertainty (e.g., geophysics for direct $\mathrm{Cr}$ delineation). There is some concern about the validity of the analytical techniques used in cases where stained vadose zone soils do not show high concentrations of Cr.

The investigation was generally successful for the 100D Area, and its methodology may be applicable elsewhere at Hanford. The highest concentration of $\mathrm{Cr}(\mathrm{VI})$ found to date in Hanford groundwater, 40,000 $\mu \mathrm{g} / \mathrm{L}$, was recorded during this study and the putative source was refined to a $100 \mathrm{~m} \times 100 \mathrm{~m}$ area. The outcome of this research highlights the need to establish balanced criteria for remediation and for determining when site excavation is appropriate after a source area has been identified. The overall project performance and inter-organizational collaboration (e.g., to provide samples for geochemistry) were commended by the review panel.

Lessons Learned: This relatively low tech strategy was able to greatly reduce the uncertainty about the origin of the chromium contamination and refine the size of the source area, enabling potential treatment strategies that were initially ruled out because of the high cost of using these strategies on a very large area. More expensive techniques may be viable if the treatment volume or area is small. Although this specific technique may not be directly transferable to many DOE sites, the overall strategy of using low tech but high confidence strategies (e.g., historical data, drilling, basic transport understanding, etc.) should be considered at every waste site.

Path Forward: The methods employed in this project should be applied to other suspected source zones at Hanford and elsewhere. Because the project has been completed, no further funding from EM-22 was recommended for the chromium source in the Hanford 100D Area. The panel was encouraged by the strong collaboration demonstrated during this project as well as the commitment/effort by DOE and site contractors (e.g., Fluor) to incorporate the lessons learned into the future baseline. The results of this study should lead to an improved focus on remediation technologies (such as chemical reduction methods) that can treat high concentration source areas jointly in the vadose zone and groundwater. This is an appropriate area for future EM-22 funding. 


\subsection{ISRM Barrier mending with zero valent iron}

Consensus Recommendation - Finish field injection as planned and then have independent panel review results to support decisions regarding applicability of the technology at Hanford or elsewhere.

Summary of Review: The original microscale zero valent iron (ZVI) did not perform as expected in the bench tests, delaying the project. The investigators identified a nanoscale ZVI as a replacement reagent, and it will be field-tested this year. ZVI injection in the field was proposed for early August, 2008, with final report submission scheduled for mid-December. This interval is likely too short for accurate determination of the shortterm performance of the nanoscale ZVI, given the large volume $(370,000 \mathrm{~L})$ of injection solution to be used. As noted in the 2006 review, injection of large quantities of water may displace chromium-contaminated groundwater and temporarily skew the results observed at monitoring wells. The field research also will not provide any information about the endurance of nanoscale ZVI. Unless monitoring and assessment of iron retention and speciation is extended well past the current endpoint of this project, the lifetime and need for replenishment of iron cannot be determined. Soil coring for performance monitoring will be collected at only one point, a new well approximately 12 meters from the injection point. It is preferable to obtain cores from additional locations to corroborate the iron distribution data obtained from geophysical characterizations and to identify any problems (or benefits) caused by preferential flowpaths. Field analyses were recommended to address concerns raised in the 2006 regarding carbonate precipitation, increased $\mathrm{pH}$, ammonia production, and ecological impacts of an anaerobic plume. The current project doesn't appear to address these concerns.

ZVI is a proven reducing compound. Injection of particulate ZVI has been successfully used in commercial subsurface cleanup applications for several years. Although the Hanford bench scale tests appeared to have been performed carefully and indicate that the tested nanoscale iron will remove $\mathrm{Cr}(\mathrm{VI})$ and should adequately persist in the subsurface, the cost of the selected nanoscale iron will likely be prohibitive. The panel recommends finishing the currently planned field test and writing the final report. The final report should include a careful, inclusive, and accurate cost assessment for using the tested/selected technology. Assuming typical application rates of $1 \%$ of soil, the cost of material alone is $\$ 1100$ per ton of soil treated (assuming $\$ 55 / \mathrm{lb}$ of the selected ZVI material used in the field test) versus $\$ 11$ per ton of soil treated (assuming $\$ 0.55 / \mathrm{lb}$ for typical ZVI material). At $\$ 1100$ per ton, the selected treatment material would have limited application for this site, for other DOE sites, or for commercial projects. However, because the injection scheme for this project was flawed and because an expensive amendment was selected for demonstration, this should not be used as a definitive basis to preclude the use of zero-valent iron to mend the ISRM barrier or for other applications at DOE sites.

Objectives: The project's original goal was to increase the longevity of the ISRM barrier by restoring its reductive capacity using injection of micron-sized ZVI particles and shear-thinning polymer. The iron would be injected to flow into the permeable areas of the ISRM barrier where poor performance (in terms of barrier longevity and treatment 
effectiveness) has been observed. The iron then reacts with contaminated groundwater to convert Cr(VI) to Cr(III), thus decreasing both mobility and toxicity. Performance assessment was to be performed using existing wells and cores taken from the injection area. The EM funded project cost was $\$ 1,050 \mathrm{~K}$. Field injections were to begin August 4-15, 2008. The final project report is due December 15.

Project Performance: The peer review completed December, 2006 addressed several topics including the following:

o Delivery of ZVI - To support ZVI delivery through wells, a weighted series of criteria to select the best candidate from a series of ZVI products was discussed. The criteria included particle size, surface area, cost, and \% Cr reduction as measured in batch tests. Issues and associated recommendations to address the challenges heterogeneity and permeability were also provided.

o Presence of co-contaminants and by-product generation - Presumably to be evaluated during bench-scale testing and field testing. These data were not provided to the panel.

o Longevity - To be evaluated during bench-scale testing.

The summary recommendation from that review was to re-scope the laboratory work and rapidly move to demonstrate it in the field. A decision was made to subcontract (through a bid process) as a turnkey project including laboratory work, modeling and injections in the field.

This project has changed scope significantly since it was originally peer reviewed in December 2006. These changes resulted in part from the problems found with the type of ZVI originally specified for the laboratory testing. It is still unclear why the micron-scale ZVI didn't work as it had been tested in the PNNL laboratory twice earlier and the panel expressed concern that communication with PNNL during the troubleshooting on this topic was insufficient. There were also concerns about the replacement with nanoscale iron, as it could be too reactive and not be delivered far enough into the formation. The project at the date of review consisted solely of results of the laboratory testing, which was a proof of principle applied science project, rather than the original scope.

Other deviations from what was recommended by the December 2006 review:

1. The review panel recommended injection only in targeted intervals of high permeability rather than through the entire screened interval in the existing wells. This is important, because it significantly impacts the cost of the technology, its practical implementation, and whether it would ever be selected as an alternative for mending the barrier. Even the project manager expressed concern regarding the likelihood that the technology would be implemented full-scale due to cost considerations. If the demonstration had been designed as recommended by the earlier expert panels, it might be more cost effective.

2. The panel recommended a robust program to monitor the performance of the injection, but we are unclear as to whether that is being done.

a. Monitoring should include assessment of the chemical effects of the injection, including changes in $\mathrm{pH}$, nitrate and ammonia concentrations etc. Specific monitoring parameters that are planned are unclear, as the panel was not given the Treatability Test Plan. The panel recommended 
monitoring of co-contaminants and polymer byproducts, including the generation of ammonia, high $\mathrm{pH}$, mobilization of other metals, and generation of explosive conditions due to methane and hydrogen. Laboratory analytes should include hexavalent chromium, total chromium, nitrate, nitrite, ammonia, sulfate, hydrogen, methane, iron, manganese, arsenic, other metals with potential for mobilization, and any other possible byproducts of injection.

b. Include DO monitoring in downgradient wells and along the river shoreline (aquifer tubes) to determine whether the iron injection has effects beyond those currently imparted by the barrier.

c. The panel also recommended use of cross borehole geophysics if possible. It appears that only surface geophysics (ER and EM) will be used and the likelihood of that working is low. The reviewers noted that it is unlikely that single well geophysical methods (i.e. EM, resistivity, etc.) will respond to ZVI alone, however a co-injected electrolyte (e.g., salt) might provide some indication of how far the bulk injectate has spread.

d. Coring of only one borehole at one location is not a robust enough performance monitoring method, as the injection will likely not be in a uniform cylinder around the injection screen. Coring at only one location will not provide evidence of overall performance. The demonstration could have been set up taking advantage of existing wells for monitoring and possibly installing a small diameter injection well with injection points only at the depth of the "preferential pathway." In this way, monitoring points could have been located close to the injection well.

3. The previous panel recommended laboratory testing for specific objectives of identifying production of byproducts, including explosive gases, such as methane and hydrogen, and ammonia, and monitoring the effects of $\mathrm{pH}$. Another potential issue could be effects of the polymer. It appears that most of the lab testing was focused on selection of iron and didn't address the issues recommended by the panel.

4. A pre- and post-test study of the injection well was recommended to assess changes in hydraulic conductivity. 
After reviewing the MSE report "Summary ZVI Evaluation for the Micron-Sized Zero-Valent Iron (MZVI) Injection Project” (September 14, 2007), the reviewers identified several practical questions about the materials selected for column and field testing. In general, the work appeared to be systematic and goal oriented. The weighted evaluation of different types of ZVI was a good approach to select candidates for further testing, but the weighting values were not carefully applied. In the private sector, the main considerations for treatment technologies are:

1. Will the technology adequately achieve the goal - in this case will the material adequately reduce $\mathrm{Cr}$ and persist for the required time period.

2. Can the technology be applied at the selected site - in this case, can the ZVI be safely and adequately emplaced and distributed in the required location(s).

3. Is the technology acceptable to the stakeholders - in this case, it is assumed that all of the iron proposed is equally acceptable.

4. Cost.

A negative response to any of the first three questions eliminates the technology. For the remaining technologies, the fourth consideration, cost, then serves to select the technology and should be directly factored appropriately in any weighting scheme. It is not clear why one of the materials (QMP H2OMet-XT), was not selected for additional testing. This material is approximately 100 times less expensive ( $\$ 0.55 \mathrm{vs} \$ 55 / \mathrm{lb}$ ) than the ZVI materials selected; it adequately removed $\mathrm{Cr}$ in batch testing. Although it has not been field tested, there is no adequate reason presented in the report that would suggest that its application would be more complicated or risky than any of the other ZVI materials. In particular, the size related criterion from Zhang (2005) does not demonstrate the necessity for exclusion of the larger particle size iron in this application of ZVI.

Lessons Learned: The review panel recognized that the poor performance of the initially planned ZVI material was unforeseen and the type of challenge that is expected in an applied science effort. Nonetheless, there were several important lessons from this project:

1. Improved communication is needed - for example to enagage PNNL during the troubleshooting period

2. Better use of external resources/expertise and industry knowledge is possible. The information and support of independent and outside experts from earlier expert panels and peer reviews was often not put into beneficial use nor was the experience from commercial practitioners.

3. Improved project management, contracting and control are needed.

Path Forward: Funding has been supplemented by RL, Fluor and MSE. No further EM22 funding is recommended at this time. Instead, the review panel supported completion of the currently funded scope and completion of the project reports. Due to the problems to date on this project, the panel recommended a review of the project reports and results by independent experts to support any decisions regarding applicability of the technology. 


\subsection{ISRM barrier supplementation with upgradient biostimulation}

Consensus Recommendation - Finish and incorporate into feasibility study and remedial alternative analysis. Technology should be considered to support a comprehensive remediation for $\mathrm{Cr}(\mathrm{VI})$ at $100-\mathrm{D}$ and could be used at other 100 Area and Hanford sites.

Summary of Review: The review panel commended the investigators for good project management and controls. It is notable that prior to funding the project scope was modified twice in response to peer review comments. The major revisions shifted the work from industrial chemical reductants, to an expensive carbon substrate, and ultimately to less expensive carbon substrates such as molasses and vegetable oil. The overarching goal of the project is to refine and develop a technology to remove oxygen and other electron acceptors from the groundwater (along with some fraction of the $\mathrm{Cr}(\mathrm{VI})$ ) and therefore to provide protection to the ISRM barrier and increase its efficacy and longevity. The laboratory work and molasses field deployment have been completed and the vegetable oil deployment is scheduled. When complete and the results documented, the approach will be ready for incorporation into field activities, as appropriate, to meet the overarching chromium goals for the 100D Area. The reviewers provided a number of specific comments and suggestions. Most important was that this type of project should utilize available design guides and offsite resources to minimize cost and maximize cost the potential for success.

Objectives: The goals of this research were to perform laboratory studies and large-scale field testing to determine the effectiveness of biostimulation for creating a geochemically reduced (e.g., low oxygen) zone upgradient of the ISRM barrier, thereby contributing to a "defense-in-depth" remediation of the chromium plume at the 100D Area. Biological activity and reducing conditions were to be stimulated in separate scenarios using the addition of rapidly-biodegraded molasses or more slowly-degraded vegetable oil. The EM funded project cost was $\$ 1,958 \mathrm{~K}$. Molasses injections and follow-up have been performed. Emulsified vegetable oil injections are planned for August or September, 2008 and will be followed by monitoring every two months.

Project Performance: The December 2006 peer review recommended dramatically revising the original ISRM barrier supplementation proposal. Specifically, the reviewers recommendations included: 1) utilization of inexpensive carbon substrates as electron donors (rather than aggressive short lived reagents such as calcium polysulfide), 2) designing the process as part of a "defense-in-depth" concept to work in concert with other planned 100D activities, and 3) use of recent industry experience related to carbon substrate based groundwater remediation to help optimize the applied research and field testing. The initial revision of the proposal used a nonstandard application of an available carbon substrate - introducing unnecessary deployment uncertainty and risk. The second revision of the proposal was funded by DOE and was generally consistent with 1\&2 of the 2006 recommendations (above). This funded work included two types of substrates, a carbohydrate (molasses) and an emulsified vegetable oil substrate, to be tested in medium scale laboratory tests (mobility and distribution in Hanford specific sediments) and in pilot field tests. 
The review panel provided the following comments for the researchers:

- The panel continues to support the use of an inexpensive electron donor - the molasses and emulsified vegetable oil to be tested are good choices as would be agricultural byproducts (e.g., carbohydrates) that might be potentially available from local sources.

- Many alternative emplacement methods would work for this relatively simple concept - these include infiltration galleries or perhaps direct-push injection points/lances. The use of large injection wells with the associated costs at Hanford might be able to be eliminated in some cases (but these practical issues were not addressed in the research in favor of basic science substrate migration studies in the laboratory). Injection well delivery may also suffer from inadequate distribution related to aquifer heterogeneity, as demonstrated downgradient in the ISRM barrier. Some of the monitoring data suggest that incompatible chemicals (i.e., documentation of methanogenesis at the same time as elevated chromium concentrations) are occurring in different parts of the aquifer, which are then mixed when sampling a monitoring well.

- The reviewers encouraged Hanford to consider how this research fit with planned schedules for the 100-D Area remediation to make sure that it could be used if appropriate.

- The reviewers recommend expanded monitoring of the field tests, both spatial and temporal if possible.

- $\quad$ The Cr(VI) measured in several wells at the same time as sulfate reduction and methanogenic conditions should be examined. If the reducing conditions are present throughout the sampled zone, then $\mathrm{Cr}(\mathrm{VI})$ should be below detection. These results suggest the potential for significant heterogeneity that might reduce effectiveness.

- As with other chemical reduction techniques, creating anoxia near the river/hyporheic zone could have adverse impacts (potentially as bad as having low levels of $\mathrm{Cr}(\mathrm{VI})$ ). The reviewers suggest addressing some of these issues with project resources - possibly in lieu of measuring Cr isotopes.

Lessons Learned: Avoid duplicating work already reported in the literature for future projects. Several reviewers noted that the applied science goals (working toward improved protection of the Columbia River) could have been successfully met with less laboratory work and more focus on moving to the pilot field test and relying more on the scientific and engineering literature. In this case, there was nothing unique or particularly challenging about the Hanford application. Existing literature (lab studies and large numbers of deployments in a variety of settings) combined with the Department of Defense funded and published engineering and design guides could have been beneficially used to maximize progress toward the congressionally mandated goals at significantly reduced costs. Acceleration of the field testing would have enabled the results to be incorporated into the remedial process optimization work underway by the site cleanup contractor. 
Path Forward: The vegetable oil field work should be completed as planned, after which the project will be ready for incorporation into field activities, as appropriate, to meet the overarching chromium goals for the 100D Area. When completing the work, the researchers should consider the peer review comments the extent practicable. Also, the researchers should revisit available design guides and offsite resources to maximize the potential for success. The project is on-track for completion and additional EM-22 funding is not recommended. The reviewers commended the researchers on both work quality and work control. 


\subsection{Projects Addressing ${ }^{90} \mathrm{Sr}$}

Two applied research projects were performed to address ${ }^{90} \mathrm{Sr}$ in the groundwater in the Hanford 100 Areas near the Columbia River:

Surface infiltration of apatite solution (4.1)

Phytoextraction (uptake in Coyote Willow) (4.2)

These technologies supplement the baseline groundwater remediation efforts at Hanford. 


\subsection{Surface infiltration of apatite solution}

Consensus Recommendation -The majority favored "Finish" with a minority of the panel advocating "Discontinue." (split finding)

Summary of Review: Realistic progress toward application of apatite-forming solution for ${ }^{90} \mathrm{Sr}$ immobilization requires an applied focus and experiments that provide information that can realistically be used, given reasonably achievable field characterization. The investigators have devoted a great deal of effort to represent nuanced field conditions (e.g., zones of low permeability and variable water content), both numerically and in small-scale physical models, so that the various factors that impact apatite formation and distribution could be examined with the long-term objective of helping tailor infiltration strategies. However, it is unlikely that subsurface characterization can achieve the resolution that would be necessary to modify apatite solution infiltration to the degree tested in the experiments. While the experimental scope (tasks and schedule) were well articulated in the initial proposal, the focus was almost entirely on lab tests. A field research component, or a clear path toward moving the concept to the field, is needed to make this work relevant to potential use. Lack of a field component was troublesome to the reviewers, because this vadose targeted research was positioned as an extension of ongoing full-scale deployment of apatite-forming solution below the water table - much of the previous lab research should support this variant and thus it shouldn't require duplication. Performance metrics and a strategy related to how the information generated in this research would improve protection of the Columbia River were weak.

Objectives: The goal of this project was to extend the strategy for administering apatiteforming solution to sequester ${ }^{90} \mathrm{Sr}$ in the vadose zone of the $100-\mathrm{N}$ Area. Thus, the research was intended to address surface infiltration through the vadose zone. Most of the ${ }^{90} \mathrm{Sr}$ contamination at this site is located above and in the vicinity of the water table. This project targets such vadose contamination to support potential application within about $100 \mathrm{~m}$ of the riverbank (because of attenuation processes, this is the portion of the ${ }^{90} \mathrm{Sr}$ plume that is a significant risk for discharge to the river). Small-scale column studies, 2-D experiments, and numerical modeling were proposed to elucidate apatite formation and strontium sequestration following infiltration of a calcium-citratephosphate solution. The EM funded project cost was $\$ 790 \mathrm{~K}$

Project Performance: The December 2006 technical peer review was supportive of this project but recommended better connection and support for transitioning from the laboratory to full-scale field application. Specifically, the peer review observed that this project is “...too focused on the microcosm-level to adequately answer field questions". The peer review recommended that experimental testing and modeling be followed with field testing. Although large-scale sediment column testing is planned, this is very different than actual field testing and provides little or no information about the significance and role of heterogeneity at the field scale. The 2D sandbox experiments have added very little to what we already know about vadose zone infiltration. 
Digressions into foam and microbial fate are of some interest, but were out of scope and not of primary interest for decisions about applying this technology.

A primary recommendation of the 2006 peer review was the inclusion of “ . . a detailed description of the alternative selection process, as well as a compelling argument for choosing this alternative." This recommendation appears to have been overlooked. Alternate means of introducing apatite-forming solution, i.e. through injection rather than trench infiltration, were recommended in the 2006 review, but do not appear to have been considered. There is a significant concern regarding reagent delivery at 100-N Area, especially because of the road bed material and diesel co-contamination. At the review workshop, there was discussion about installation of a shallow horizontal well to deliver the amendment. If Hanford were to move to implementation, they should work with industry consultants regarding practical approaches.

The experimental results suggest concern about mixing of the chemicals to make the apatite in a porous media. The process depends upon a number of complex reactions that could be very difficult to control in the subsurface. Sequestration of ${ }^{90} \mathrm{Sr}$ by apatite was relatively slow and may not be able to be practically implemented. Given that the data indicate significant complexity of this process in effectively producing apatite in situ, a comparison of the apatite-forming solution strategy with alternative strategies is critical. This proof-of -principle test implies that the technology may not be effectively delivered to the subsurface in a real world situation.

The potential for colloidal transport of strontium on apatite particles was identified as an issue in the 2006 review and was not examined.

There was little coordination with the polyphosphate team - this specific coordination was recommended in the 2006 technical review and improved overall coordination was a benchmark requirement in the enabling Congressional mandate that funded this research.

Lessons Learned: This project produced several great experiments that have provided important information including measured rates of ${ }^{90} \mathrm{Sr}$ incorporation into apatite and required apatite mass loading to sequester ${ }^{90} \mathrm{Sr}$. Unfortunately, microcosm and small sandbox experiments are of limited use in developing full-scale field application parameters. Pilot-scale applications of new technologies are vital to help bridge the gap between expected behaviors discovered on the lab bench and the uncertainty unavoidably encountered at full field scale. This is why the 2006 peer review was firm on recommending focused-limited lab studies and including a field component.

Path Forward: If DOE moves forward to complete this effort with the in-place EM-22 funding, the researchers should consider the peer review comments to the extent practicable. At a minimum, the researchers should produce an applied science product that identifies the state of knowledge ("what is known") and how that knowledge supports actions to protect the Columbia River. Further, appropriate technical assessment of alternatives should be performed and documented in the final report. If the apatite generating solution infiltration process is shown to be unreliable, if the research raises as many technical questions as it answers, or if field application is not robust to real-world conditions (e.g., heterogeneity and characterization uncertainties), then Hanford should move efficiently to an alternative strategy. Supplemental EM-22 funding is not 
recommended at this time. Interesting basic science issues identified in the research should be funded by the Office of Science as necessary. 


\subsection{Phytoextraction (uptake in Coyote Willow)}

Consensus Recommendation - Finish both subparts of this project and evaluate data to determine viability and acceptability for application.

Summary of Review: This effort comprises two separately funded projects: a) a field study to address questions related to optimal management of Coyote willow to support deployment for phytoextraction of ${ }^{90} \mathrm{Sr}$, and b) a food chain uptake and transfer study. Both projects are addressed together in this section. The reviewers note that reasonable progress has been made on this research despite flooding. In 2006, peer reviewers emphasized performance metrics, potential collateral impacts, and realistic lifecycle costs. The project team has addressed many of these issues in a reasonable manner. Based on the investigators' data, it appears that additional information is needed to provide meaningful estimates of the ${ }^{90} \mathrm{Sr}$ flux that is likely to be captured by a willow barrier at the $100 \mathrm{~N}$ Area. Of note is that depth profiles of ${ }^{90} \mathrm{Sr}$ have been underutilized in this effort, instead, soil cores collected along the shoreline at different depths and locations were homogenized prior to being sampled for ${ }^{90} \mathrm{Sr}$ activity and used in greenhouse studies. It would be helpful to determine depth profiles for ${ }^{90} \mathrm{Sr}$ in $100 \mathrm{~N}$ vadose zone porewater and shallow groundwater, since plant uptake of strontium is expected to be proportional to concentration. Similarly, the distribution of willow root biomass for trees grown in the 100K Area riparian test plot was not determined (this will of course depend on tree age and growth conditions). This information, combined with ${ }^{90} \mathrm{Sr}$ uptake data from greenhouse studies, would improve estimates of ${ }^{90} \mathrm{Sr}$ uptake and help establish potential "capture zone" design predictions for willows of various ages. These data could also be used to estimate the ${ }^{90} \mathrm{Sr}$ flux to the river that might bypass the willow barrier, for example from transport beneath the root zone. A clear conceptual model of the ultimate proposed remediation strategy will be key to regulatory and stakeholder acceptance and the viability of the concept.

Objectives: Phytoextraction near the Columbia River shoreline, used in combination with other methods of sequestration/removal for ${ }^{90} \mathrm{Sr}$, has the potential to contribute to a comprehensive "defense in depth" strategy. The phytoextraction effort investigates how a specific plant (Coyote willow) may be used along the Columbia River corridor to extract ${ }^{90} \mathrm{Sr}$ from the deep vadose zone and shallow groundwater and incorporate the contaminant into aboveground biomass for periodic collection and disposal. The effort uses greenhouse studies and field tests to answer questions about the best ways to grow and fertilize the fast growing plants for maximum biomass production, ${ }^{90} \mathrm{Sr}$ extraction, and river protection. It also performs assessments of ${ }^{90} \mathrm{Sr}$ uptake by insects feeding on willow biomass. The field studies were funded in the original (2006) portfolio of projects and the effort was expanded in 2007 with additional funding/scope to address potential stakeholder concerns related to food chain transfer and potential remediation induced export of ${ }^{90} \mathrm{Sr}$. EM-22 provided two rounds of funding for this project totaling \$783K. The reviewers noted that Fluor is supplementing that investment, demonstrating commendable collaboration. 
Project Performance: As a general note, there are a variety of phytotechnology techniques that have been explored in the literature. The techniques that use macroscopic plants as part of environmental remediation have been broadly designated as phytoremediation. Some phytoremediation methods remove contaminants from the subsurface, some help stabilize or sequester contaminants, some remove water from the subsurface, and some contribute to organic contaminant breakdown. In a general sense, it is useful to distinguish these technologies and use terms such as phytoextraction, phytosequestration, phytoevapotranspiration, and phytodegradation. While all of these technologies (and others such as wetland treatment systems) are in the broad class of phytoremediation, it is sometimes helpful to employ a name that clearly and succinctly communicates both the use of plants and the remedial objective. This in turn can assist in developing goals for the treatment strategy and in defining performance criteria and monitoring plans. The Coyote willow project is phytoextraction.

The field portion of the project has been effective for testing the establishment and growth of Coyote Willows in a riparian environment. The project meets the stated objectives of the proposal (Phytoremediation - Treatability Study Along the 100-N Riparian Zone). The location of the field plot is in an area with high groundwater and an area that is subject to inundation from seasonal river flows. The riparian area that is the focus of the remediation appears to be much different from the test plot location - an area with very coarse soils, fluctuating groundwater levels and a significant rip rap armor that is protecting the riverbank. Also, several performance issues can not be addressed in this study since the test plots were planted in an area that is not contaminated with ${ }^{90} \mathrm{Sr}$. The willows performed well within the test plot and reasonably addressed fertility and management issues, planting techniques and initial biomass production. There are several issues that still need to be addressed - these include a better understanding of the rooting characteristics of the Coyote willow under conditions of a highly fluctuating water table and the projected biomass production of mature Coyote willows grown in a poor soil environment. Key results of the field work include:

- Coyote willows are a hardy species and are well suited to grow in riparian areas along the Columbia River.

- Coyote willows can withstand extended periods of flooding and survive.

- Biomass production during the first year of the study is acceptable for young plants. Biomass production of mature plants grown in the riparian area of the Columbia River is not known.

- Plant uptake of ${ }^{90} \mathrm{Sr}$ is assumed to be in direct relation to the (Ca: $\mathrm{Sr}$ ) ratio in soil water (based on laboratory studies).

- Active management activities including fertilization and weeding of test plots is necessary

The uptake and food chain transfer effort is a well designed laboratory study. The bulk of the study focused on Sub-Task 3, which was an aphid feeding study. Aphids were placed on plants grown in contaminated 100-N sediment and fed on sap from plants. The aphids were collected from plants, counted and analyzed for ${ }^{90} \mathrm{Sr}$. The results of the aphid portion of the study indicate that exudates (honeydew) produced by the insects should not be a significant source of contaminant export. The results of the laboratory study were scaled up to a theoretical field implementation of the proposed phytoextraction along the 100-N Columbia River riparian zone using a "worst case" 
scenario. The results of that scenario indicate that ${ }^{90} \mathrm{Sr}$ that might be deposited in exudates by aphids would be below detection limits. Key results of the field work include:

- There should be no measurable changes in ${ }^{90} \mathrm{Sr}$ concentrations in soils from honeydew deposits from aphids feeding on contaminated Coyote willows.

- The researchers developed growth chambers using plants grown in 100-N contaminated sediments that may be applicable for use in testing various transitory insects that may accumulate ${ }^{90} \mathrm{Sr}$ and may be applicable to other sites and contaminants in the future.

Lessons Learned: The project has highlighted the difficulty of working in a dynamic and variable environment. These data suggest that native plants such as Coyote willow have the potential to perform well and to provide some robustness if incorporated into a comprehensive remediation strategy. The potential viability of phytoextraction and the realistic potential for real-world application will ultimately hinge on acceptance by regulators and stakeholders. A lifecycle conceptual approach, supported by clear, concise and compelling information, a monitoring plan, and contingencies are crucial to such acceptance. Even if the research documents technical feasibility, stakeholders are likely to express significant discomfort extracting a contaminant radionuclide into a surface ecosystem on the shoreline of the Columbia River. In addition to those being studied, a variety of scenarios for food chain transfer are possible (e.g., contamination of insect larvae such as Western Yellow-Striped Army Worm and/or Alfalfa Looper) feeding on plant material grown in soil contaminated with ${ }^{90} \mathrm{Sr}$. The reviewers of the current work recommend that in completing this work, the researchers consider other such scenarios that might be postulated and eliminate as many as possible through data, site management practices, and by calculation based on ${ }^{90} \mathrm{Sr}$ activity in various plant tissues. Further, the reviewers believe that more data on the distribution and quantity of root biomass, and documentation that roots will actively intercept the contaminated sediments is needed to improve confidence in a phytoextraction strategy.

Path Forward: The reviewers recommend Finish for both projects that support this effort. In completing the work, the researchers should attend to several outstanding issues that will be important to moving forward with incorporating phytoextraction into the overall remediation along the 100-N Columbia River Riparian zone. The review panel identified (below) several suggested activities to improve the potential applicability and viability of phytoextraction, but the panel does not necessarily recommend additional EM-22 funding at this time unless a clear signal can be obtained from regulators and stakeholders that they are likely to permit the concept based on the already funded activities.

The success of phytoextraction of ${ }^{90} \mathrm{Sr}$ from the soil and groundwater is dependent upon the root distribution of the Coyote willow. Additional work is needed to evaluate how the Coyote willow roots are distributed in the subsurface. Willows are very hardy and can survive during extended periods of time when the woods are submerged in groundwater. This has been demonstrated during the current study. What is more important is how deep the roots will penetrate into the subsurface. Another important question to answer is will the roots follow the water table as it lowers during the year or 
will they focus on the thin capillary fringe above the water table. An important aspect in moving forward will be to excavate a number of mature willows and track the rooting patterns and distribution in the subsurface.

A second issue is the need to determine if the willows, growing in the riparian environment of the Columbia River, will produce sufficient biomass to remove the projected amounts of ${ }^{90} \mathrm{Sr}$ from the soil and groundwater. This can be answered by continuing the existing study for an additional year or two until the willows begin to reach maturity.

Task 4 of the food chain transfer project is designed to evaluate the potential for insects that consume foliage and tender shoots to accumulate ${ }^{90} \mathrm{Sr}$. According to researchers Task 4 studies will be implemented later this year. Data from the initial study and the forthcoming Task 4 will provide reasonable information on the potential risks of off-site transfer of ${ }^{90} \mathrm{Sr}$ by insects. 


\subsection{Project Addressing Uranium}

One applied research project was performed to address uranium in the groundwater in the Hanford 100 Areas near the Columbia River:

o Polyphosphate injection (5.1) 


\subsection{Polyphosphate injection}

Consensus Recommendation - Finish. Any future work deemed necessary by DOE (e.g., to verify the long-term stability of uranium-bearing minerals produced by polyphosphate amendments in the vadose zone) would be appropriate for funding through the Office of Science, possibly as part of the activities at the field research site in the 300 Area of Hanford.

Summary of Review: The panel recommends completing the project. The field demonstration of polyphosphate injection into the saturated zone yielded significant results, namely, that polyphosphate amendment as applied did not form sufficient mineral precipitates for saturated zone treatment in the 300 Area. There were a variety of reasonable and plausible hypotheses about the underperformance. In general, however, the dominant factor controlling underperformance was the hydrogeologic and geochemical heterogeneity found at the field scale. This is an important and cautionary finding, because the laboratory and theoretical work that led up to the field test was high quality and the general approach used to adapt the technology to a large scale application was defensible - similar to many of the other in situ remediation technology projects being pursued at Hanford. The underperformance in a real-world setting highlights the limitation of attempting to resolve all technical uncertainties through lab and column testing. Further, this reinforces the recommendations in previous peer reviews that emphasize well conceived performance metrics and a focused plan that moves steadily through lab and column studies toward well-designed and controlled field pilot tests. For example, an earlier technical peer review of this project recommended push-pull testing as a lower-cost field effort that could eliminate a portion of the lab work and improve the potential for success in the large-scale field activities (e.g., by providing more realistic data to adjust the polyphosphate blend and by examining performance at an intermediate scale). However, this approach to delivery and testing was not followed. Based on the results of the field testing to date, deep vadose and capillary fringe targets may have greater promise. The reviewers also encourage improved collaboration with other groups in PNNL (e.g., those studying in situ apatite formation and those operating the 300 Area uranium field test bed for the Office of Science).

Objectives: The project objective was to perform laboratory and field tests to determine the efficacy of using polyphosphates for in situ stabilization of uranium in the 300 Area vadose zone and aquifer. The basis for the polyphosphate addition is that it would hydrolyze and release phosphate with the goal of precipitating uranium-bearing phosphate minerals, potentially allowing remedial objectives to be met. The study was based on careful laboratory work and sought to determine the feasibility of full-scale deployment of this method at the site and to develop cost estimates for doing so. The EM funded project cost was $\$ 3,045 \mathrm{~K}$

Project Performance: The researchers addressed several of the recommendations of the 2006 peer review. For example, the researchers examined calcite sequestration as well as the role of supersaturated calcite conditions (typical of Hanford groundwater) in autunite formation. The research used the unsaturated flow apparatus to great advantage to 
examine behavior of polyphosphate flow and transport in unsaturated conditions and used actual contaminated sediments to test the performance of polyphosphate amendments. The reviewers noted the following specific issues:

o The limited information provided did not document if all the laboratory tests proposed were actually conducted. If they were, were they realistic? The presentation did not match the initially proposed tasks. Metrics for this project were weak.

o Delivery is a big issue, especially with the change in water table and hydraulic conductivity of the aquifer. Researchers did not take the advice from the prior peer review to use push pull injection as part of the field activities.

o "Mixing" of the amendments in the groundwater was difficult. Several reviewers were concerned that "mixing" in the vadose zone might be equally difficult and challenged the idea presented to the panel that the vadose deployment will be a preferred method. The consensus is that appropriate delivery and mixing would be challenging.

o The researchers were trying to form autunite and they found none formed. Thus, the hypothesis for the proof-of-principle testing was not demonstrated. The uranium was found to be sorbed on calcite, which will be more soluble and thus may not have longevity.

The planned intermediate scale testing to be completed will probably not add a significant amount of additional information relevant to field injection at the site. Unsaturated flow at this scale has been modeled many times before.

There was little coordination with the team studying injection of calcium-citratephosphate to precipitate apatite to sequester ${ }^{90} \mathrm{Sr}$ - this specific coordination was recommended in the earlier 2006 technical review and improved overall coordination was a benchmark requirement in the enabling Congressional mandate that funded this research. Work addressing the deep vadose zone and capillary fringe has helped refine polyphosphate composition for improved reaction kinetics. The investigators' research has been of high quality and is potentially relevant to the objectives of the Columbia River Program. This work should contribute to the uranium-related research at the field test bed in the 300 Area that is being funded by the Office of Science. The review team noted that communication and collaboration between research teams is essential as both projects progress.

Lessons Learned: The tasks in the project were well managed and completed in a timely manner. Notably, the large scale field injection was completed, but issues related to impacts of heterogeneity in site hydrogeology and geochemistry, i.e. the autunite product didn’t form, resulted in significant underperformance. Based on the data, the panel concluded that the technology, as originally scoped for groundwater treatment, does not currently have sufficient information to justify deployment. Further, the underperformance highlights the general need for Hanford and PNNL to develop an approach for applied research that emphasizes moving out of the laboratory and into the field in an efficient and effective manner. 
Path Forward: The current project should be completed as planned. Future work to verify the long-term stability of uranium-bearing minerals produced by polyphosphate amendments to the vadose zone would be appropriate for funding through the Office of Science. The reviewers encourage the researchers to modify or reduce the scope of the planned intermediate scale tests in the laboratory and make sure that they address important project specific uncertainties and unknowns. 


\subsection{Project Addressing Carbon Tetrachloride}

One applied research project was performed to address carbon tetrachloride (also known as CT, tetrachloromethane or carbon tet) in the groundwater in the Hanford 200 Areas near the Central Plateau:

o Measuring hydrolysis/degradation rates (6.1) 


\subsection{Measuring hydrolysis/degradation rates}

Consensus Recommendation - Finish. As originally scheduled, this work plan spanned 4 to 6 years, with EM-22 Columbia River supplemental funding for 2 years and an alternate source of funding in the out years if "tangible progress is demonstrated." The project has performed well and the review panel supports completing this effort.

Summary of Review: This project is on schedule and has been well managed. This study addresses one of the largest and most challenging plumes at Hanford and the data may be critical in resolving cleanup strategy at the Hanford site. The hydrolysis rate for carbon tetrachloride and chloroform in the aquifer system will determine if the solvent plumes in the groundwater will stabilize (and then shrink over time) prior to impacting the Columbia River. That determination, in turn, will help determine if a difficult, multifaceted, and expensive groundwater treatment strategy for organic solvents is required, or if a strategy that relies on natural attenuation including hydrolysis to protect the Columbia River is viable. While this project is relatively straightforward, it must be carefully performed with a high level of quality assurance to accurately determine reaction rates in sealed containers over several years. This is a project that benefits by attention to detail. The investigators have done a commendable job in the organizing and carrying out the work. The PNNL collaboration with academia was a notable positive feature of this project, although it was not clear why so much of the work was duplicated in its entirety at both institutions. Some reviewers expressed concern over specific details of the project (see below), but the general consensus was positive. This work was well performed and should directly contribute to the congressionally mandated goal of improving the protection of the Columbia River.

Objectives: The goal of this laboratory project is to improve the ability to predict natural attenuation of carbon tetrachloride and chloroform in the groundwater beneath and downgradient of the Hanford 200W Area. The studies elucidate abiotic decomposition processes, particularly hydrolysis, in the presence of mineral surfaces and at realistic field temperatures. This study extends previous research that examined only homogeneous (aqueous phase) hydrolysis rates to examine if the presence of sediments accelerates hydrolysis rates. Quantification of the contribution of hydrolysis to overall pollutant degradation is crucial if monitored natural attenuation is to be proposed as a remediation strategy. The EM funded project cost was $\$ 309 \mathrm{~K}$.

Project Performance: The goal of the project was to identify the potential contribution of heterogeneous hydrolysis to chlorinated solvent degradation in sediment/groundwater from the Hanford 200 West Area. The peer review panel expressed concern about the emphasis on pure, standard minerals such as kaolinite and montmorillonite in laboratory tests. While some tests with natural sediments are included in the study, much of the effort/resources are expended on the pure minerals; the selection of the minerals for testing has not been justified in terms of mechanism or hypothesis. The researchers suggested that the pure mineral tests will allow them to generalize the results to a broader set of environments and different mineralogical conditions but the proposed approach was not provided to the review panel. Note that the 2006 review panel emphasized this 
issue and recommended that the selection of minerals be reevaluated and justified. Some reviewers expressed concern over the small scale of the experiments, further emphasizing the need for a rational and technically based approach for upscaling.

The lowest tested temperature is $20^{\circ} \mathrm{C}$; this temperature is more realistic than prior research but is still a few degrees higher than expected field values - errors in extrapolating the results to 15-18C should be minimal, however. Several experiments are duplicated in entirety at Hanford and in Peter Jeffer's laboratories in the Chemistry Department the State University of New York (SUNY) Cortland. It is appropriate to replicate some of the work in independent labs but the use of different methods (e.g., custom glassware versus standard ampoules with headspace, phosphate buffer, etc.) and the lack of a clear documented basis for the scope overlap is a weakness during a time of limited resources.

The research results to date appear to be of high quality and provide some early exciting potential - both for low temperature rates and related to the impact of sediments in increasing rates in heterogeneous versus homogeneous systems. These early results suggest a measurable increase in the rate of hydrolysis at low temperature when sediment is present.

Lessons Learned: Carefully focused and targeted basic science study of key processes can contribute to developing and improving sitewide remediation strategies. In this case, physical chemistry research on hydrolysis rates may be the key to a rational sitewide strategy for the organic solvent plume in the groundwater at Hanford. For this to happen however, more emphasis on developing a clear technical strategy for applying the data to the field will be needed.

Path Forward: In the 2006 peer review, the panel recognized that this research "will likely take between four to six years to complete..." and that resources from the Columbia River Protection Supplemental funding " is only provided for two years...." The reviewers at that time concluded that "subsequent funding will need to be secured to complete the study..." and that such additional funding should be predicated on "tangible progress ...demonstrated after two years." The reviewers concluded that tangible progress has been demonstrated. One of the Hanford operating contractors, Fluor, has begun providing partial funding for this project. This collaboration and integration of the supplemental activities into the "baseline" was commended by the reviewers. In completing the work, the reviewers recommend more attention to the work scopes of Hanford and SUNY-Cortland, to assure that maximum benefit is realized from the funding and that the researchers focus some effort on how the small scale tests can be applied to a groundwater plume with a footprint of several square kilometers. Results from these experiments should be shared as rapidly as possible. This information could be vital to the disposition of current remediation activities as well as the long term cleanup strategies at the site. 
Appendix A

Short Biographies of the Technical Review Panel Members 


\section{David L. Cocke}

Dr. Cocke holds the Gill Chair in Chemistry at Lamar University in Beaumont TX and is a Professor in the Dept. of Chemical Engineering. He is also an Adjunct Professor of Physics at Texas A\&M University. He is the Director of the Texas Engineering Experiment Station (TEES) Statewide Materials Initiative, Deputy Director of the TEES Center for Electrochemical Systems and Hydrogen Research, Director of the Lamar University Fuel Cells and Energy Systems Center, Director of the Lamar Digital Pedagogy in Science and Engineering Laboratory, and the Director of Science and Technology Development for the College of Engineering at Lamar University. He received his $\mathrm{PhD}$ in Chemistry and Physics from Texas A\&M University in 1972. He was a postdoctoral fellow at Texas A\&M until 1974, during which he was a visiting scientist at the Max Planck and the Franz Haber Institutes in Germany. Dr. Cock is recognized for his contributions to the fields of: environmental surface chemistry and catalysis, advanced materials, biomedical research and capillary electrophoresis, and advanced electrochemistry and environmental sensors. His diverse research accomplishments have advanced these fields, particularly with regard to a detailed understanding of complex electrochemical and catalysis reactions and the applications of such processes to environmental applications. Dr. Cocke has more than 400 publications. Examples of his recent papers include: Electric Fields in Environmental Catalysis, Potential of Modified Zirconium Oxide as Environmental Catalyst, Ettringite Formation in Large Volume Industrial By-products and Their Applications in S/S of Arsenate and Chromate, Capillary Electrophoretic Study of Dibasic Acids of Different Structure Relation to Separation of Oxidative Intermediates in Remediation. Dr. Cocke has substantively contributed to the technical literature related to EC and the potential for application EC to various types of wastewater. Dr. Cocke is active in the American Chemical Society, Electrochemical Society, Society of Applied Spectroscopy, National Association of Corrosion Engineers, Materials Research Society - Coal Combustion Byproducts Utilization Group, and the American Institute of Chemical Engineering Industrial Needs Workshop committee.

\section{Paul C. Deutsch}

Mr. Deutsch is a Principal Soil Scientist with AMEC Geomatrix, Inc. in Fresno, California with over 30 years of experience in the environmental field working primarily with industrial clients on various aspects of soil science and agronomy. Mr. Deutsch's experience includes evaluating the fate/transport of heavy metals in soils; performing soil and plant nutrient uptake studies, designing and implementing large scale phytoremediation programs; and performing soil and land classification surveys. In addition, Mr. Deutsch provides company wide expertise for irrigation management, salinity management, and evaluation of disposal alternatives for wastewater. Mr. Deutsch is currently implementing phyotechnologies at several project sites in California and in New York. The California locations are employing the use of phreatophytic trees including poplars, eucalyptus and willow species for nitrate removal from soil and groundwater and for hydraulic control of a high water table beneath a closed landfill. The site in New York is employing the use of arsenic hyperaccumulator plants to 
phytoextract arsenic from surface soil adjacent to a former manufacturing facility. Mr. Deutsch is a certified professional soil scientist and agronomist and is recognized for his expertise in soils, irrigation management, agronomic issues and phytoremediation. He is a graduate of Colorado State University with a degree in Soil Science and Agronomy.

\section{Dawn S. Kaback}

Dr. Kaback has more than 30 years of experience in a technical and management role in research and technology development for environmental and energy issues. She has a reputation for successful implementation of innovative solutions for environmental problems for a wide range of problems, primarily focused on contaminated groundwater and soil investigation/remediation. Her work has spanned from research through practical applications, technology assessments, and strategic planning. She has dedicated significant efforts to transfer of innovative technologies from government laboratories to commercial practice and holds three patents for an innovative remediation system for in situ groundwater treatment. Dr. Kaback has provided technical advice for unique environmental problems at numerous DOE sites, ranging from retrieval/treatment of radioactive waste to in situ groundwater treatment. She has successfully demonstrated project management skills through management of multi-million dollar government environmental programs, including six years at the Savannah River Laboratory. Dr. Kaback has served as a technical advisory expert and on numerous expert panels/peer reviews for the DOE, its contractors, and the National Academy of Sciences. She has taught numerous workshops for the National Ground Water Association (NGWA), served on their Board of Directors, served as an editor of Ground Water Monitoring and Remediation for 10 years, and as editor of Ground Water News and Views. Dr. Kaback has shared results of her work through delivery of more than 50 presentations at various nationally recognized conferences and related venues. She recently received the prestigious Keith O. Anderson Award from NGWA for her continuing service to the organization.

\section{Eugene J. LeBoeuf}

Dr. Leboeuf is an Associate Professor of Civil and Environmental Engineering at Vanderbilt University in Nashville TN. He received his undergraduate degree in Civil Engineering from the Rose-Hulman Institute of Technology in 1985, a M.S. in Industrial Engineering and Management Science from Northwestern University in 1986, a M.S. in , Civil Engineering from Stanford University in 1993 and a $\mathrm{PhD}$ in Environmental Engineering from the University of Michigan in 1998. Dr. LeBoeuf supports the Consortium for Risk Evaluation with Stakeholder Participation (CRESP) and has been active in providing independent technical assistance to DOE - including serving as cochair of the 2006 technical peer review of the Columbia River applied research projects. Dr. LeBoeuf is recognized for his research in the inter-related fields of physicochemical processes, water security, and bioinformatics of environmental systems. He has made significant contributions to the understanding the relationships between soil structure and chemistry to the availability of contaminants and the risk to potential receptors. His efforts in water security include evaluation of novel vulnerability assessment methods 
and deployment of new information technologies to help protect punlic water sources. He has investigated an array of biological informatics sensors to assess the potential for protozoa to act as scavengers and refuges for pathogens in the environment. He has developed novel microfluidic devices to study predator-prey interactions between protozoa and bacteria. Experiments with these devices are elucidating the physical behavior of biological systems, and how this behavior impacts the ability for bacteria to degrade pollutants. Dr. LeBoeuf has been active in the US Military Reserves and has also performed research and service in Military Engineering.

\section{Brian B. Looney}

Dr. Looney received his undergraduate degree in environmental science from Texas Christian University, Ft. Worth TX, in 1978, and his doctorate degree in Environmental Engineering from the University of Minnesota, Minneapolis MN, in 1984. Dr. Looney is a senior fellow environmental engineer at the Department of Energy Savannah River National Laboratory (SRNL) in Aiken SC and an adjunct professor in the Environmental Engineering Science Department at Clemson University. Dr. Looney coordinates development and deployment of innovative environmental characterization and clean-up methods at the Savannah River Site, and serves as a technical advisor supporting the DOE Environmental Management Program. Dr. Looney has worked at SRNL for 25 years, during which time he has developed, tested and deployed a wide range of environmental characterization and clean-up methods for organic and inorganic contaminants and radionuclides. Brian has successfully completed a wide variety of environmental research projects to improve subsurface access (e.g., horizontal drilling and cone penetrometer), improve remediation (e.g., sparging, bioremediation, and thermal methods), and improve characterization (e.g., tracer testing, soil gas methods and geophysics). Currently, Brian is a principal investigator on a program to evaluate natural attenuation of chlorinated solvents and to develop techniques to enhance aerobic cometabolism for these contaminants. He received the Citizens for Nuclear Technology Awareness (CNTA) Fred C. Davison Distinguished Scientist (2006), National Groundwater Association Technology Award (2005), American Chemical Society Industrial Innovation Award (2004), Federal Laboratory Award of Excellence in Technology Transfer (1996 \& 2000), Worlds Best Technology Award (2004), and Energy 100 Award (2000). Brian has a large number of publications including the recent book Vadose Zone Science and Technology Solutions. 


\section{Joe Rossabi}

Dr. Rossabi earned a Ph.D. in Environmental Engineering from Clemson University, an MS in Environmental Engineering from the University of North Carolina at Chapel Hill, and MS and BA degrees in Physics from the State University of New York at Binghamton. Dr. Rossabi is principal scientist and part owner of Redox Tech, LLC where he applies innovative remediation solutions, including hydraulic fracturing, steam injection, chemical injection (for oxidation or reduction of contaminants), and metals stabilization, to soil and groundwater contamination. Prior to Redox Tech, he was a fellow engineer in the Environmental Sciences and Technology Division of the Department of Energy's Savannah River National Laboratory where he performed applied research and development of environmental characterization and remediation technologies and strategies. His research involved field-testing and implementation of cone penetrometer-based characterization and remediation methods, multiphase flow processes including DNAPL fate and transport, and passive and renewable energy powered methods for characterization and remediation of subsurface contaminants.

\section{Karen L. Skubal}

Dr. Skubal coordinates national applied science research activities for EM-22, the DOE EM Office of Groundwater and Soil Remediation. She received her undergraduate degree in Chemical Engineering from Northwestern University, her M.S degree in Environmental engineering from Carnegie Mellon University, and her PhD in Environmental Engineering from University of Michigan. Internationally, she has collaborated as a visiting researcher at the Korea Advanced Institute of Science and Technology (KAIST), Taejon, South Korea, and the Institute of Physical and Chemical Research (RIKEN), Wakoshi, Saitama, Japan. Dr Skubal served on the faculty in the Environmental Engineering program at Case Western University from 2000-2007. She is recognized for her research in biotic and abiotic reductive dechlorination processes for halogenated solvents under iron- and sulfate-reducing conditions in contaminated aquifer sediments. Other research interests include chromium biotransformation, biodegradation of airport deicing compounds, bioconversion of agricultural and food-processing wastes, and phytoextraction of heavy metals for brownfield restoration. 
Page 49 of 54

\section{Appendix B \\ Detailed Review of Electrocoagulation}




\section{Supplemental Detailed Review for Electrocoagulation}

Principal Reviewer:

Dr. David L. Cocke

Gill Professor of Chemical Engineering

P. O. Box 4942, College Station, TX 77840

With contributions from the remaining panelists.

\section{Introduction}

Fluor Hanford, Inc. (FH) proposed, designed and assembled a pilot electrocoagulation (EC) system to test this alternative technology for $\mathrm{Cr}$ (VI) reduction to $\mathrm{Cr}$ (III) and removal of the latter's subsequent species by association with iron oxyhydroxides and oxides. The main goal was to demonstrate that the Balance of Plant and its operation, including the cleaned water injection were of potential for effective treatment at a reduced cost. FH oversaw the pilot-scale treatability test with the primary purpose of the study to determine the effectiveness of $\mathrm{Cr}(\mathrm{VI})$ removal and to test the robustness/ implementability of an EC system. The secondary purposes of the treatability study were to determine information about derivative wastes and to obtain data applicable to scaling the process from the pilot treatability scale to full scale.

The heart of the EC pilot plant is the EC reactor. Properly designed and operated EC reactors will clean the water of dissolved $\mathrm{Cr}(\mathrm{VI})$ and prepare the resulting solids for removal. An improperly designed and/or operated EC reactor will cause subsequent problems in meeting the removal target and result in complex and intractable operational problems. The Electrocoagulation Industry has been plagued by the apparent simplicity of the process and the EC reactor. Nothing can be further from the truth. The multiple electrodes in EC reactors require complex solution chemical and electrochemical reactions be controlled and the strong tendency of electrodes to foul call must be mediated by careful and sophisticated electrochemical engineering. This discussion will focus on the EC reactor from the information provided to the review panel (DOE/RL2008-13).

The Basis of Selection of the EC Reactor and the Negative Consequences According to FH, the EC 132 to $284 \mathrm{~L} / \mathrm{min}$ (35 to $75 \mathrm{gpm}$ ) Reactor was purchased from Ecolotron, Inc. based on the following:

- Safety: The pressurized unit maintains evolved gases in solution until they can be released in a controlled manner, thus mitigating the potential undesirable gas buildup.

- Integrity: The heavy, tubular, steel frame provides durability and strength. This design is less likely to be damaged in transit or onsite during operation/maintenance due to its robust construction. 
- Performance: Due to flow turbulence generated inside the plate and frame stack, this design is reported by the manufacturer to be less likely to experience scale buildup within the unit than other designs.

- Maintenance: The plate and frame stack facilitates controlled draining, and it opens fully for easy access during plate replacement or scale removal.

Taking these criteria in order:

- Safety: The pressurization of the EC Reactor to maintain gases in solution and elsewhere may have unanticipated consequences since gas bubble production and movement helps mass transport and helps prevent fouling. This could be partially responsible for spotty performance.

- Integrity: The EC unit design, based on a standard plate and frame configuration was aesthetic but the heavy construction is unnecessary for EC and the electrode shape was atypical and difficult to optimize. In addition, the configuration did not allow full utilization

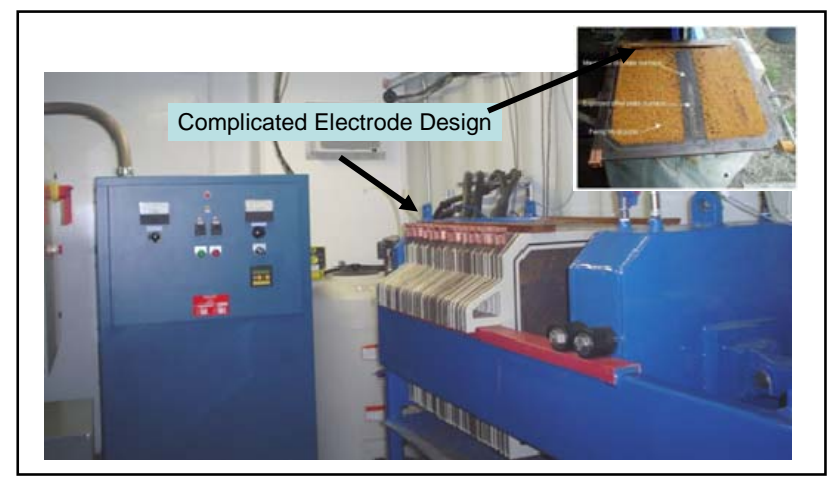
of the electrode surfaces and resulted in a slit design for water flow from one electrode separation to another. This is not a proper flow pattern for EC reactors.

- Performance: Flow turbulence was not sufficient in the EC Reactor to minimize fouling and scale build-up. The manufacturer claims are overly optimistic. Other designs have exhibited better fouling performance.

- Maintenance: The plate and frame stack design requires complicated sealing of each electrode and does not allow optimum flow patterns to be established. The use of standard plate and frame materials might initially appear to be an advantage, but resulted in over engineering of the reactor which added cost and limited flexibility to optimize electrode separations, and gas handling capabilities.

The Report states that the Ecolotron EC unit had 27 steel plate electrodes (61 cm by 61 cm by $64 \mathrm{~cm}$ [24 in. by $24 \mathrm{in}$. by $0.25 \mathrm{in}$.]) stacked in a pressurized plate-and-frame arrangement but failed to clearly specify how the electrodes were connected to the electric circuit. Alternating anode cathode arrangements are usually problematic. 


\section{Recommendation}

Given the above design flows the following recommendation is presented. The consensus panel path-forward recommendation is discontinue. The tests as currently practiced should be immediately discontinued as they are flawed and did not provide usable information about the viability of $\mathrm{EC}$ for the removal of $\mathrm{Cr}$ from the ground water before re-injection. The tests do not support decisions related to incorporating (or not incorporating) EC into ongoing and future EM activities. The discussion in the technical review included some potential ideas for alternative EC work if a critical need for high throughput treatment of Cr contaminated groundwater remains. Unfortunately, the weaknesses in the pilot study would necessitate starting over with an entirely new effort and would realize minimal benefit from the significant earlier investment. As noted below, the pre and post processing engineering, equipment and operations were generally good and the performance problems were generally associated with the EC reactor. The weaknesses in the EC design would require significant bench and pilot work to overcome and any such effort should include recognized experts and/or vendors. Consistent with the initial (2006) peer review recommendations, any future bench and pilot testing could/should incorporate efficiencies such as testing of small flexible and configurable treatment units rather than attempting to implement from scratch a final robust design with insufficient up front information.

\section{Project Performance:}

$\mathrm{Cr}$ is one of the easiest metals to remove from water by $\mathrm{EC}$ and requires the least residence time in the reactor as proven by many successfully operated systems particularly in the electroplating industry. The Hanford pilot test suggested that EC has potential for the target groundwater treatment application, but due to the weak conceptualization and design and inflexible construction of the EC reactor, the potential could not be adequately demonstrated. The original suggestions of the review panel to carefully consider the EC reactor from bench scale tests to scale-up with a reliable EC vendor were not executed properly and the EC reactor was considered to be mainly a ferrous ion generator. EC reactor design has strong interrelations to chemical engineering principles, to electrochemistry and to physical chemistry as well as to mass transfer and corrosion phenomena. The application of EC to any given water treatment scenario requires that the reactor system be specifically designed to handle the chemical nature of the water, the space time yield required, the minimum specific energy and materials (sacrificial anode) consumption needed, the purity of the treated water required and the operations scenario envisioned. Unfortunately, these factors were not central to the selection, design and implementation of EC at Hanford and the EC reactor used was chosen based on general construction characteristics (robustness) and on the degree of automation and the control system.

Pre and post treatment technology appeared to be properly engineered. While plant operations and practices during the EC Plant operation were generally good, improper sample characterization (e.g., a lack of duplicate field samples, improper reagents and procedures for ferrous iron analysis), improper system operation (e.g., discontinuation of air sparging and the addition of excess polymer into the EC treatment train), insufficient 
vendor experience/support, and a general lack of project oversight led to inadequate final water quality and injection well fouling.

The EC reactor design had insufficient flexibility to handle the ferric hydroxide fouling (flow driven erosive cleaning of the electrode surfaces), the resulting poor water contact to the active electrode areas, the resulting inefficient use of electrical energy, the adjustment of anode to cathode areas to generate the layered hydroxides (green rust) flocculate precursors, and minimization of the residual ferrous ion in the EC treated water. These resulted in too much operator involvement limited operational parameters to manipulate (mainly current and voltage). In spite of the reactor short comings and the resulting performance practices the researchers concluded: (reviewer comments and annotations in italics)

- EC system met $\mathrm{Cr}(\mathrm{VI})$ performance goals, but often requiring multi-pass (recycle) treatments because of poorly designed EC reactor

- Solid secondary waste met toxicity \& corrosivity criteria for disposal; with engineering/operational improvements, free liquid criterion could be met but not without a redesign and implemented $E C$ reactor

- As implemented, EC system was not reliable because of poor EC reactor design

- EC technology has potential, but would require better REACTOR design and implementation than realized in this test, more pre-design information (laboratory/bench-scale tests) would have led to an improved field test

\section{Lessons Learned}

- Additional assessment of EC unit design and operating parameters (e.g., power settings and polarity reversals will not be sufficient). This will require a competent EC reactor Vendor to provide properly designed flow, electrodes, polarity (monoor bipolar), IR drop between electrodes, and space time yield.

- Maintain consistent/stable ferrous iron production and resultant reduction of $\mathrm{Cr}(\mathrm{VI})$ will not be sufficient but a proper balance between $\mathrm{Fe}^{2+}$ and $\mathrm{Fe}^{3+}$ which requires cathode involvement must be maintained

- Minimize electrode passivation and/or fouling to improve Cr(VI) removal performance and minimize maintenance down-time will require turbulent flow and proper handling of the hydrogen gas bubbles from the cathode

- Increase the frequency of polarity reversal (e.g., 30 to 60 sec.) will not be necessary in a properly designed EC reactor since it will be part of the design parameters.

- Minimize amperage to EC unit to minimize iron scale will be more complex and will be part of the design parameters

- Control influent pH to minimize hardness scale will need to be investigated

- Minimize energy consumption will require all electrochemical engineering parameters be carefully considered in future research.

The main lesson learned is that the advice of the expert panel that reviewed the original possibilities for EC should have been followed. 


\section{Path Forward}

The overall cost of this one project was over 15\% of the supplemental Congressional allocation so the underperformance of this effort is significant. Importantly, the unit costs for this technology, as applied at Hanford, were several orders of magnitude above industry norms. Thus, the consensus panel path-forward recommendation is discontinue. This recommendation is for all activities associated with the EC pilot study conducted to date. Specifically, the technical peer review panel does not recommend investing additional resources to revise the current report -- even in a revised form, a report on the flawed EC design and the pilot activities to date will not support decisions related to incorporating (or not incorporating) EC into EM activities and will not improve the protection of the Columbia River. Consistent with the 2006 peer review, the panel recommends that Hanford continue to evaluate above ground treatment technologies if needed to meet the overarching goals for $\mathrm{Cr}$ in the 100 Areas. Any supplemental EC effort should be preceded and justified by up front calculations that provide a realistic cost evaluation documenting the possibility that EC is competitive with alternative techniques such as ion exchange and identifying the primary factors that influence cost and efficiency. Such a forward looking evaluation should have a sharply defined objective to meet the necessary performance goals and explicitly including target total treatment costs less than $\$ 15$ per $\mathrm{m}^{3}$ (i.e., less than approximately $\$ 50$ per 1000 gallons). 